\title{
Learning to Read: Should We Keep Things Simple?
}

Language and Reading Research Consortium

Corresponding author: Kate Cain, Lancaster University, k.cain@lancaster.ac.uk

Article accepted for publication in Reading Research Quarterly. 


\begin{abstract}
The simple view of reading describes reading comprehension as the product of decoding and listening comprehension and the relative contribution of each to reading comprehension across development. We present a cross-sectional analysis of first, second, and third graders ( $N=123-125$ in each grade) to assess the adequacy of the basic model. Participants completed multiple measures to inform latent constructs of word reading accuracy, word reading fluency, listening comprehension, reading comprehension, and vocabulary. In line with previous research, structural equation models confirmed that the influence of decoding skill decreased with increasing grade and that the influence of listening comprehension increased. However, several additional findings indicate that reading development is not that simple and support an elaboration of the basic model: A strong influence of listening comprehension on reading comprehension was apparent by grade 2 , decoding skill was best measured by word and nonword reading accuracy in the early grades and word reading fluency in grade 3 , and vocabulary skills indirectly affected reading comprehension through both decoding skill and listening comprehension. This new elaborated model, which provides a more comprehensive view of critical influences on reading in the early grades, has diagnostic and instructional ramifications for improving reading pedagogy.
\end{abstract}


Reading comprehension is determined by a wide range of component skills and processes (Kendeou, van den Broek, White, \& Lynch, 2009; Oakhill \& Cain, 2012; Vellutino, Tunmer, Jaccard, \& Chen, 2007) making the specification of such models a challenge. In this article, we evaluate a relatively simple but influential framework of reading comprehension, the simple view of reading (Gough, Hoover, \& Peterson, 1996; Hoover \& Gough, 1990; Snow, 2002). The original article (Hoover \& Gough, 1990) has made a substantial impact on the field of reading research, with more than 1,000 citations to date. However, as we outline herein, the simplicity of this framework has been questioned in recent years. Understanding the validity and adequacy of the original model compared with more complex models is important for two reasons: In relation to theory, the simple view has influenced the examination and explanation of reading development and disability across languages; in relation to practice, the simple view has informed both the diagnosis of reading disability and educational practice.

\section{The Simple View of Reading: An Overview}

According to the simple view, the knowledge, skills, and processes that determine reading comprehension are captured by two broad skill domains: decoding and listening comprehension. Thus, according to this view, reading comprehension is the product of an individual's ability to read words and to understand texts that are presented aurally. Gough and Tunmer (1986) used the label decoding, rather than word recognition, to emphasize the importance of letter-sound correspondence rules in the reading of English. We prefer the term word recognition to include the reading of words automatically through sight because of repeated exposures, in addition to phonological decoding skills (Ehri, 2014).

Gough and Tunmer (1986) defined decoding (hereafter word recognition) as the ability to read isolated single words "quickly, accurately and silently" (p. 7) and listening comprehension 
as the ability to take lexical information and derive sentence- and discourse-level interpretations. There is broad agreement of the importance of both skill sets to the prediction of reading comprehension (de Jong \& van der Leij, 2002; Megherbi, Seigneuric, \& Ehrlich, 2006; Muter, Hulme, Snowling, \& Stevenson, 2004; Oakhill, Cain, \& Bryant, 2003; Pazzaglia, Cornoldi, \& Tressoldi, 1993). In addition, twin studies demonstrate distinct genetic influences for each (Olson, Keenan, Byrne, \& Samuelsson, 2014).

The simple view makes two influential predictions about reading development and difficulties. First, the relative weightings of these two components-word recognition and listening comprehension —will change across development, as the developing reader acquires faster and more automatic word recognition skills (Gough et al., 1996). Second, poor reading comprehension may arise because of difficulties in the domain of word recognition, listening comprehension, or both (Gough \& Tunmer, 1986). There is broad support for these two central claims. Diachronic change in the influence of word recognition and listening comprehension is evident in cross-sectional studies, which show that the relation between word recognition and reading comprehension lessens with chronological age and that the association between listening and reading comprehension increases (Catts, Hogan, \& Adlof, 2005; Gough et al., 1996). Struggling readers with core deficits in word recognition, comprehension, or both have been identified across a range of alphabetic orthographies and educational settings (Cain \& Oakhill, 2006b; Catts, Adlof, \& Weismer, 2006; Catts, Hogan, \& Fey, 2003; Megherbi \& Ehrlich, 2005; Protopapas, Simos, Sideridis, \& Mouzaki, 2012; Torppa, Tolvanen, Poikkeus, Leskinene, \& Lyytinen, 2007). Our focus here is on the validity of the simple view for describing reading during the first few years of formal instruction. 
In recent years, a series of papers have proposed that the simple view lacks complexity and, therefore, validity in relation to both components: word recognition and listening comprehension (Adlof, Catts, \& Little, 2006; Joshi \& Aaron, 2000; Kirby \& Savage, 2008; Tunmer \& Chapman, 2012). As such, researchers have argued that additional components should be included. First, we detail the reasons to expect developmental change between grades in the prediction of reading comprehension and our hypothesis testing approach to determine the point of change. Second, we consider the alternative models that have been proposed for both word recognition and listening comprehension and outline our approach to testing these competing theories.

\section{Does the Simple View Capture Changes in Reading Development Over}

\section{Time?}

Whereas numerous studies support the basic premise of the simple view that a combination of word recognition and listening comprehension explains large amounts of variance in reading comprehension, it is likely that the relative contributions of these constructs change across grades. Individual differences in word recognition should be the primary contributor to reading comprehension in the first years of formal education because the focus of instruction is on teaching students to read words. In the later grades, however, the vocabulary, grammar, and discourse demands of reading materials increase, and word recognition skills become more automatic. As a result, the simple view predicts that students' listening comprehension should account for more unique variance in reading comprehension than does word recognition in older age groups.

This pattern is confirmed by reviews of the literature and a recent meta-analysis (Garcia \& Cain, 2014; Gough et al., 1996), but few studies have empirically confirmed these 
observations. One empirical study that addressed this developmental pattern used a series of regression analyes to determine the unique influence of word recognition and listening comprehension to reading comprehension in a longitudinal sample of students tested in grades 2 , 4, and 8 (Catts et al., 2005). The researchers found that the unique contribution of word recognition to reading comprehension decreased over time from $27 \%$ in second grade, $13 \%$ in fourth grade, and finally $2 \%$ in eighth grade. The reverse pattern was revealed for listening comprehension and reading comprehension; listening comprehension contributed $9 \%$ in second grade, $21 \%$ in fourth grade, and $36 \%$ in eighth grade.

The Catts et al study together with the reviews, provides compelling evidence for the broad developmental changes proposed by the simple view. However, the method for measuring these changes was regression analyses, which do not account for measurement error among measures. Furthermore, in recent years, a series of studies have demonstrated that the characteristics of assessments can greatly influence the extent to which reading comprehension is predicted by word recognition (Cain \& Oakhill, 2006a; Cutting \& Scarborough, 2006; Garcia \& Cain, 2014; Keenan \& Betjemann, 2006; Keenan, Betjemann, \& Olson, 2008; Nation \& Snowling, 1997). For example, some measures of reading comprehension may be more heavily dependent on word recognition if a cloze format is used where the selection of the appropriate word completion requires discrimination among similarly spelled distractors (Cain \& Oakhill, 2006a; Keenan et al., 2008; Nation \& Snowling, 1997). Finally, none of the developmental tests of the simple view to date have pinpointed the grade at which the shift from word recognition to listening comprehension as the predominant predictor of reading comprehension occurs, because measures were not given in concurrent grades but rather tested at grade intervals. 
A key objective in our analyses was to determine changes in relative contributions of word recognition and listening comprehension to reading comprehension in the early years of formal education, grades $1-3$, using structural equation modeling, which takes into account measurement error.

\section{Should Word Reading Fluency Be Added to the Simple View?}

Good word recognition is essential for accessing the meaning of written text. As noted previously, Gough and Tunmer (1986) defined word recognition as the ability to read isolated single words "quickly, accurately and silently" (p. 7). Clearly, that definition cannot be operationalized easily for research purposes: If words are not read aloud, how does the researcher know whether they are read accurately? Assessments of silent reading fluency include tests of comprehension, which are therefore not pure measures of word recognition (Wagner, Torgesen, Rashotte, \& Pearson, 2010). The majority of studies have, therefore, assessed word recognition using tasks that require participants to read words aloud. These research studies differ in terms of the statistical procedures used to assess the contribution of word recognition to reading comprehension, but they also differ markedly in the tasks used to measure word recognition. Some studies include measures of word recognition that have real word stimuli, whereas others use nonwords; some have used tasks that involve reading single words, whereas others measure reading words within a text; and some studies use tasks that measure accuracy, others measure how quickly items are read, and still others measure both.

A particular focus in recent years has been on the issue of whether accuracy alone is sufficient or whether a measure that also taps fluency is required. This is because when word recognition is efficient - that is, when an individual can rapidly retrieve accurate phonological and meaning-based representations of written words - greater cognitive resources are available 
for comprehension processes (Perfetti, 2007). However, the nature of the best measure of the word recognition component in the simple view might change over the course of development and by orthography. In the early stages of reading development, word recognition will be slow and more error prone, thus a measure of accuracy alone might be sufficiently sensitive to capture variance in a sample; later in development, a fluency measure may be a more sensitive indicator of word recognition skills when accuracy is easily achieved (Garcia \& Cain, 2014). In orthographies that have a very transparent relation between graphemes and phonemes (the letters and the sounds in the spoken language that they represent), accuracy is achieved quickly, and measures that assess fluency have a greater influence on reading outcomes early on (Florit \& Cain, 2011).

Fluency is a complex construct that has been defined as "a level of accuracy and rate where decoding is relatively effortless; where oral reading is smooth and accurate with correct prosody; and where attention can be allocated to comprehension" (Wolf \& Katzir-Cohen, 2001, p. 219). In practice, many standardized measures of fluency comprise word lists (rather than connected prose) and/or do not assess prosody. For that reason, the definition of fluency (or efficiency) that we follow in this research "is the oral translation of text with speed and accuracy" (Fuchs, Fuchs, Hosp, \& Jenkins, 2001, p. 239), although we note that reading with accurate expression or prosody is considered an essential part of fluency (Arcand et al., 2014; Kuhn, Schwanenflugel, \& Meisinger, 2010; Young \& Bowers, 1995).

Fluency of word reading has been measured in different ways. Some measures can be considered proxy measures of word reading fluency because the stimuli that are processed are not words, such as recording how long it takes to name a given array of (drawn) objects (Johnston \& Kirby, 2006) or letters (Joshi \& Aaron, 2000; Silverman, Speece, Harring, \& 
Ritchey, 2013). Other measures directly assess word reading fluency but differ as to whether the stimuli are presented out of context (words or nonwords in a list; Adlof et al., 2006; Kershaw \& Schatschneider, 2012; Protopapas et al., 2012; Silverman et al., 2013) or in connected prose (Adlof et al., 2006; Høien-Tengesdal \& Høien, 2012; Kershaw \& Schatschneider, 2012; Silverman et al., 2013). The fluency index can either be calculated as reading speed (words per minute) or reading time (seconds per correct word or passage), and some measures take into account word recognition accuracy as well.

The extant literature does not provide a consistent picture of the role of word reading fluency in the prediction of reading comprehension. When naming speed for objects is used as the index, it explains a small, but significant, proportion of variance in unselected samples of fourth and fifth graders but does not predict variance additional to accuracy of word reading for third graders (Johnston \& Kirby, 2006). In contrast, letter naming speed explains significant additional variance in third graders' reading comprehension outcomes (Joshi \& Aaron, 2000). When we consider reading of single (out of context) words or pseudowords, fluency forms a construct distinct from accuracy (Protopapas et al., 2012), indicating that, theoretically at least, both accuracy and fluency should make unique contributions to word recognition and, therefore, reading comprehension. Consistency of findings is not even apparent when researchers have used multiple indicators of both accuracy and fluency and/or measured fluency of connected prose. Some studies show that fluency explains additional significant variance for students older than fourth grade over word reading accuracy (Kershaw \& Schatschneider, 2012; Tilstra, McMaster, van den Broek, Kendeou, \& Rapp, 2009), whereas others do not (Adlof et al., 2006; Høien-Tengesdal \& Høien, 2012). 
This review demonstrates that word reading fluency, although important in the acquisition of skilled reading, is not necessarily a better indicator of word recognition than accuracy in the simple view of reading. However, we do not have a complete understanding of the role of fluency, and whether its contribution to reading comprehension is separable from and additional to word reading accuracy, because of the design of these studies. First, we know of only three studies that have directly tested whether accuracy and fluency are separable constructs, and these studies report contradictory patterns of results. In the first, Adlof et al. (2006) examined word reading fluency in second-, fourth-, and eighth-grade U.S. students with measures of single word reading (grades 4 and 8 only) and connected prose (all three grades). For the two younger groups, word-level skills made a significant contribution to reading comprehension in addition to listening comprehension, but the contributions made by fluency and accuracy were not separable. This stands in contrast to Silverman et al.’s (2013) study of fourth graders that demonstrated a distinction between fluency and accuracy. On turning to a younger sample, Protopapas et al. (2012) found a distinction between accuracy and fluency of single words and nonwords in Greek readers in grades 1-3. Greek is a transparent orthography, thus we might expect fluency to be important earlier in reading development than for a more opaque orthography such as English (Florit \& Cain, 2011).

One objective in our analyses was to test the role of fluency in the prediction of reading comprehension in consecutive age groups of young readers, which will speak to the issue of whether the separability of accuracy and fluency are age and language dependent.

\section{Should Vocabulary Be Added to the Simple View?}

In the simple view of reading, listening comprehension represents the ability to take lexical information and derive sentence- and discourse-level interpretations. Note that in the context of 
the simple view, listening comprehension refers to the ability to understand a discourse-level text spoken aloud to a student that is parallel in structure to the reading comprehension assessment (Hoover \& Gough, 1990). The critical role of high-quality meaning-based (i.e., lexical) representations to support integration and inferential processes is well established (Perfetti, 2007; Perfetti \& Stafura, 2014). As a result, it has been proposed that independent assessments of vocabulary should be included in the simple view of reading, beyond tests of listening comprehension.

Studies that include independent assessments of vocabulary find that it explains additional variance in reading comprehension over and above word reading in young adults (Braze, Tabor, Shankweiler, \& Mencl, 2007; Cunningham, Stanovich, \& Wilson, 1990; Ransby \& Swanson, 2003) and students in grades 4-9 (Tilstra et al., 2009). However, those studies did not test the specificity of the link between vocabulary knowledge and reading comprehension: Is vocabulary a subcomponent of the construct of listening comprehension, or does it also feed into reading comprehension through the construct of word recognition because it taps the quality of lexical representations (Braze et al., 2007; Mitchell \& Brady, 2013; Perfetti, 2007)? In addition, some have argued that the additional variance explained by the inclusion of a vocabulary measure is an artifact of measurement error: These findings might arise because the measures of vocabulary are highly reliable (typically from widely used standardized IQ tests) in contrast to the often more experimental measures of listening comprehension (Protopapas et al., 2012). Indeed, when the factor structure of listening comprehension has been tested, a one-factor model that includes independent measures of vocabulary and passage comprehension is as good a fit as the two-factor model (Protopapas et al., 2012). 
With regard to the simple view, a critical issue is whether vocabulary influences both word recognition and listening comprehension. There are several studies that speak to these relations. Studies of younger populations typically find that vocabulary predicts either concurrent (Ouellette \& Beers, 2010) or longitudinal outcomes in reading comprehension but not word recognition (Muter et al., 2004). In contrast, when students above grade 3 are considered, vocabulary influences both word recognition and reading comprehension (Ouellette \& Beers, 2010). A further test of these relations in 7-year-olds supports this viewpoint (Tunmer \& Chapman, 2012). Using a latent construct approach, Tunmer and Chapman found that listening comprehension fed into reading comprehension directly, and also indirectly through its influence on word recognition. They did not test, however, whether vocabulary was the specific basis for this mediating link.

An objective in our analyses was to determine whether the addition of vocabulary improves the fit of the model and, if so, whether its influence on reading comprehension is through word recognition, listening comprehension, or both.

\section{Current Study}

In the current study, we used structural equation modeling, within the framework of the simple view of reading, to examine the relation between word recognition (both accuracy and fluency) and vocabulary, listening comprehension, and reading comprehension in a large, cross-sectional sample of students in grades $1-3$. The following research questions guided our study:

1. Does the basic model of the simple view of reading, including only word recognition and listening comprehension, provide a good estimation of reading comprehension in grades $1-3$ ? 
2. Does the influence of word recognition and listening comprehension on reading comprehension change across grades?

3. Do accuracy and fluency of word recognition make separable contributions to the determination of reading comprehension?

4. Does vocabulary improve the prediction of reading comprehension, and if so, is vocabulary's influence through word recognition, listening comprehension, or both?

\section{Method}

\section{Participants}

The participants in this study were part of a larger comprehensive longitudinal investigation of reading and listening comprehension in preschool to third-grade students. The current sample included all participants in grades 1-3 during the initial year of that study. There were 125 first graders, 123 second graders, and 123 third graders. Table 1 shows the mean age, income status, gender, ethnicity, percentage receiving free or reduced-price lunch, and special education status of students at each grade and whether English was the home language. These data indicate that our sample was racially and ethnically diverse, and included children with Individualized Education Plans and from families living below the poverty level.

Students were selected from four research sites in different regions of the United States, with each site responsible for approximately the same number of students at each grade. Across research sites, school districts were selected based on size and diversity of the student populations, as well as willingness to participate in the project. Once districts (and principals) agreed to participate, cooperating teachers in the relevant grades received recruitment packets to send home for all students in their class. Among those children whose parents consented to 
participation, we randomly selected approximately 32 students per site per grade to receive our assessment battery.

\section{Measures}

Our assessment battery included multiple measures of reading comprehension, word recognition, listening comprehension, and vocabulary. Each of the measures of these constructs is described next. The assessments were administered in the latter half of the school year (January-May).

\section{Reading Comprehension}

Three measures of reading comprehension were administered. The Gates-MacGinitie Reading Test (MacGinitie, MacGinitie, Maria, \& Dryer, 2000) has different levels of the reading comprehension subtest for our three different age groups. For first graders, the level 1 passage comprehension task was administered, and second graders received level 2 . The written passage is presented in units of one or more sentences, and from four corresponding pictures, students select the one that matches the meaning of the sentences. The grade 3 students completed the level 3 materials in which the passage is presented as a whole, and are required to answer questions (with multiple-choice responses) after each one. Students were given 35 minutes to complete the task, and the score was the number of items correctly selected. The internal consistency (Cronbach's $\alpha$ ) for our sample was good across grades 1-3: .89, .82, and .91, respectively.

The passage comprehension subtest from the Woodcock Reading Mastery TestsRevised: Normative Update (WRMT-R/NU; Woodcock, 1997) was also administered to assess students' reading comprehension. This measure employed a cloze procedure in which students read a short passage with one or more words missing and were required to provide the missing 
word(s). The internal consistency (Cronbach's $\alpha$ ) for our sample from grades 1-3 was good: .91, .87 , and .89 , respectively.

We also administered an experimental measure, the Reading Comprehension Measure (RCM), which was adapted in part from the fifth edition of the Qualitative Reading Inventory (QRI-5; Leslie \& Caldwell, 2010). The RCM assessed students' abilities to read, comprehend, and answer inferential and noninferential questions about narrative and expository passages. Students read the passages silently and notified the examiner when each passage had been read. The examiner then asked sets of open-ended questions for each passage. First graders read one expository and two narrative passages, whereas second and third graders read two expository and two narrative passages. None of the passages overlapped. Five passages came from the QRI-5, and the remainder was created specifically for this project. These passages matched the gradeappropriate passages from the QRI-5 in terms of length and Lexile levels. Students' responses to administered questions were audiotaped. Trained examiners scored each audiotaped response based on a rubric of acceptable answers. The total number of correct responses served as the raw score. Approximately $10 \%$ of the sample from each grade was scored by a second examiner, and the inter-rater reliability was .93. The internal consistency (Cronbach's $\alpha$ ) for our sample from grades 1-3 was adequate: $.77, .77$, and .80 , respectively.

\section{Word Recognition Accuracy}

Two measures of word recognition accuracy were administered: two subtests from the WRMTR/NU. The word identification subtest measured students' ability to accurately pronounce printed English words ranging from high to low frequency of occurrence. The internal consistency (Cronbach's $\alpha$ ) for our grades 1-3 sample was high: .96, .93, and .93, respectively. The word attack subtest assessed students' ability to read pronounceable nonwords that increased 
in complexity (a greater number of syllables). The internal consistency (Cronbach's $\alpha$ ) for our sample was high: $.92, .91$, and .92 , respectively.

\section{Word Recognition Fluency}

Two subtests of the Test of Word Reading Efficiency-Second Edition (TOWRE-2; Torgesen, Wagner \& Rashotte, 2011) were administered to measure word reading fluency. The sight word subtest measured how many printed English words, which ranged from high to low frequency of occurrence, students could accurately pronounce in 45 seconds. The phonemic decoding subtest assessed how many pronounceable nonwords, which varied in complexity, students could accurately pronounce in 45 seconds. We did not repeat the administration of the assessment to our sample, so we report reliabilities from the test manuals. The average test-retest reliability for the sight word efficiency subtest reported in the manual is .93 for grades $1-3$. The sample reliability for the phonemic decoding subtest is .91 .

We also administered a third measure of word reading fluency in context, adapted from the Florida Assessment for Instruction in Reading: Oral Reading Fluency (ORF; State of Florida, 2009). Students read two passages aloud for up to 60 seconds (when the assessor stopped the reading if not completed). Students were forewarned that they would be asked a comprehension question after each story. This instruction was to encourage reading for meaning. Words read accurately per minute was calculated for each passage, and a fluency score for each student was obtained from the tables provided online by the Florida Center for Reading Research (www.fcrr.org/lookup). As with the TOWRE-2, we did not repeat the administration of this assessment, so we could not compute test-retest reliability for our sample. The published Item Response Theory precision estimates (using a scale similar to that used for $\alpha$ coefficients) are consistently above .85 , which is good. 


\section{Listening Comprehension}

Three measures were used to assess listening comprehension. The Test of Narrative LanguageReceptive (TNL-R; Gilliam \& Pearson, 2004) assessed students' ability to listen to three passages read aloud and answer open-ended questions pertaining to the passages. Students also completed the expressive components of this measure, but the data from these components were not used in this study. The measure was administered according to test procedures with one exception: Prior to answering questions for the second expressive passage, students were required to retell the passage. This retell was used for other studies within the larger project. Students' responses to test items were audiotaped, transcribed, and scored as correct or incorrect. The total number of correct responses served as the raw score. The internal consistency (Cronbach's $\alpha$ ) for our sample from grades 1-3 was adequate: .69, .73, and .58, respectively.

We also administered a modified version of the understanding paragraphs subtest of the Clinical Evaluation of Language Fundamentals-Fourth Edition (CELF-4; Semel, Wiig, \& Secord, 2003. This measure assessed students' ability to listen to spoken paragraphs of increasing length and complexity, understand oral narrative, and answer questions that tap a range of different skills, including inference making, story-relevant general knowledge, and accurate memory of the information presented. Similar to the CELF-4's original version, students listened to paragraphs read by the assessor and responded to sets of open-ended questions. Adaptations for our project included using two test paragraphs for each grade instead of administering three paragraphs based on students' age in the CELF-4. Also, passages in the CELF-4 were the same for grades $1-3$, but in our version, one test passage at each grade overlapped with a passage at the preceding/proceeding grade level. These modifications allowed this subtest to be administered to a wider age range of students and also decreased the amount of 
administration time per student. Regardless of grade, all students answered a total of 10 questions; their responses were audiotaped, transcribed, and scored as correct or incorrect. The total number of correct responses was tallied as the raw score. Intra-class correlations for our modified measure of the understanding paragraphs subtest of the CELF-4 range from .98 to 1.00. Reliability (Cronbach's $\alpha$ ) for our sample was poor (.01-.54 for each story).

This was an experimental measure, and it was the first time being used as such. Exploratory factor analyses resulted in a four- to five-factor structure (depending on the grade), which could explain the low reliability. Because we were using this (and other measures) to inform latent constructs, we included additional reliability checks per construct. For the constructs where Understanding Spoken Paragraphs was included, the reliability for the construct including this measure was above benchmark values (see the Structural Equation Models subsection in the Results section for further details), so we decided to retain this measure in the analyses.

We also administered an experimental measure, the Listening Comprehension Measure (LCM), which was adapted in part from the QRI-5. This measure was similar to the RCM in general format but assessed listening rather than reading comprehension. Specifically, it assessed students' abilities to listen, comprehend, and answer inferential and noninferential questions about spoken narrative and expository passages. Students listened to paragraphs read aloud by the assessor and responded to sets of open-ended questions for each. First graders heard one expository and two narrative passages, whereas second and third graders were presented with two expository and two narrative passages. None of the paragraphs overlapped. Seven passages came directly from the QRI-5, and the remainder was created specifically for this project. These passages matched the grade-appropriate passages from the QRI-5 in terms of length and Lexile 
levels. Students' responses to administered questions were audiotaped. Trained examiners scored each audiotaped response based on a rubric of acceptable answers. The total number of correct responses served as the raw score. Approximately $10 \%$ of the sample from each grade was scored by a second examiner, and the inter-rater reliability was .91 . The internal consistency (Cronbach's $\alpha$ ) for our sample from grades 1-3 was adequate: .65, .75, and .83, respectively.

\section{Vocabulary}

Three measures of vocabulary were administered. The fourth edition of the Peabody Picture Vocabulary Test (PPVT-4; Dunn \& Dunn, 2007assessed students' recognition of the meanings of spoken words. The examiner read a list of target words aloud, and the students selected one of four pictures that corresponded to the meaning of the target word. Test procedures for establishing a basal and ceiling were followed. The internal consistency of the PPVT-4 for our sample was high: .95 for all three grades.

We also administered the second edition of the Expressive Vocabulary Test (EVT-2; Williams, 2007). For this measure, students were required to provide a single word or synonym for the target word when shown a picture. Procedures for establishing a ceiling and basal were followed. The internal consistency for our grades 1-3 sample was high: .94, .93, and .95, respectively.

We also administered the word classes 1 and 2 subtest from the CELF-4. This subtest assessed students' abilities to understand relationships between words that are related by semantic class features and to verbally express the similarities and differences between those relationships. This subtest contained receptive and expressive components. For the receptive component, students listened to three or four words and chose two that were related. For the expressive component, students described the relationship between the two words they chose. 
We administered the word classes 1 subtest to first and second graders and word classes 2 to third graders. Students' responses for the expressive component were audiotaped and postscored. The total numbers of correct responses were tallied for the receptive component, the expressive component, and the two components combined. The internal consistency (combined across receptive and expressive) for our sample from grades 1-3 was good: .91, .94, and .84, respectively.

\section{Procedures}

All measures were administered by trained research staff in a quiet room within the student's school, local university site, community center, or home. Assessors underwent comprehensive training, which included the completion of online training modules (including quizzes), and inlab observations by supervising assessors to ensure consistent measurement administration and fidelity across sites. The full assessment battery took five to six hours to complete, with measures administered in prescribed blocks, each lasting 15-40 minutes. At two testing sites, measures were administered during these testing blocks in students' schools. At the other two sites, assessments were administered across one or two weekend days. In the latter case, frequent breaks were taken to ensure that students were attentive during test administration. All measures were administered individually except for the Gates-MacGinitie, which was administered in small groups or individually, where necessary.

\section{Results}

\section{Descriptive Statistics}

Table 2 reports descriptive statistics for each of our measures. In general, the assessments measure a range of abilities and increase in difficulty across grades. The correlations by grade between our variables are provided in the Appendix online. 


\section{Structural Equation Models}

We used structural equation modeling (LISREL 9.1; Joreskog \& Sorbom, 2012) to assess the relations among variables in three different theoretical models. The two typical submodels in structural equation modeling were used: the measurement model and the structural model. The measurement model, actually a confirmatory factor analysis model, specifies the relationships between the observed (or measured) variables and their underlying unmeasured latent variables. The use of multiple measures of each latent variable takes measurement error into account, thereby resulting in better assessment of each latent variable. This is a strength of structural equation modeling over other methods that are reliant on single measures and cannot take measurement error into account, such as regression analysis. The structural model specifies the directed relations among the latent variables, as shown in Figures 1-3, for each theoretical model.

Reliabilities for latent variables as used in structural equation modeling were calculated using Hancock's coefficient $H$ (Hancock \& Mueller, 2011), which captures the reliability for latent constructs. The recommended cutoff value for Hancock's coefficient $H$ is .70. Coefficient $H$ was calculated for each construct across all three models and across all three grades. For reading comprehension, construct reliability ranged from .81 to .89 . Construct reliability ranged from .89 to .98 for word recognition, from .76 to .79 for listening comprehension, and from .86 to .91 for vocabulary.

The first step in evaluating a model is to assess the fit between the theoretical model and the sample data. Because no single global fit index has been deemed acceptable (Schumacker \& Lomax, 2010), we used four measures of model fit to make a more informed judgment than with a single index. The standardized root mean square residual index considers the residuals between 
the observed and the model-implied covariance matrices. Values below .08 are deemed as indicating acceptable model fit. The comparative fit index, normed fit index, and nonnormed fit index are each scaled from 0 to 1, with values over .90 being considered acceptable. Finally, a vote count was taken across the four indexes to determine overall model fit.

For each theoretical model, estimates from the standardized solution are presented. Estimates of the factor loadings (relating the observed to latent variables in the measurement model) and the structure coefficients (relating the latent variables to one another from the structural model; these are analogous to standardized $\beta$ weights in regression analysis) are shown at the top of Tables 3-5 and the global fit indexes at the bottom.

\section{Does the Simple View's Basic Model Provide a Good Estimation of Reading}

\section{Comprehension in Grades 1-3?}

As shown in Figure 1, the first theoretical model hypothesizes that word recognition and listening comprehension together influence reading comprehension. As shown in Table 3, all of the factor loadings and structure coefficients were significantly different from zero $(p<.05)$ and in the expected direction (i.e., positive) for every grade. Model fit was also deemed to be acceptable for each grade. The $R^{2}$ statistic is additionally presented for each grade to indicate that around $90 \%$ of the variance in reading comprehension was explained by the model. These data demonstrate that the basic model of the simple view provides a good estimation of reading comprehension in grades $1-3$.

Does the Influence of Word Recognition and Listening Comprehension on Reading Comprehension Change Across Grades?

To address this question, we need to examine the structure coefficients across the grades (see Figure 1 and Table 3). In grade 1, word recognition had a much stronger influence on reading comprehension than did listening comprehension. This consecutive-grade cross-sectional 
approach helps identify when the shift from word recognition to listening comprehension occurs. There was a shift beginning in grade 2 , such that listening comprehension had a much stronger influence on reading comprehension than word recognition, with the same pattern apparent in grade 3. This is consistent with previous research (Catts et al., 2005) indicating the increasing automaticity of word recognition and the emergence of listening comprehension as the predominant predictors of reading comprehension as literacy develops.

\section{Do Accuracy and Fluency of Word Recognition Make Separable Contributions to the Determination of Reading Comprehension?}

Figure 2 displays a second theoretical model in which word reading fluency and word reading accuracy latent variables were split out from the word recognition latent variable described previously. This theoretical model posits that word recognition accuracy, word recognition fluency, and listening comprehension each independently influence reading comprehension. As shown in Table 4, all of the factor loadings and most of the structure coefficients were significantly different from zero $(p<.05)$ and in the expected direction (i.e., positive) across grades. Global model fit was acceptable for each grade. The $R^{2}$ statistic is presented for each grade, where again around $90 \%$ of the variance in reading comprehension was explained by the model. Most notable are the differential structure coefficients across the grades. First, as in the single-construct word recognition model, the strength of the influence of listening comprehension increased after grade 1 . Next, the influence of word reading accuracy decreased from grade 1 , becoming nonsignificant by grade 3 . Finally, the influence of word reading fluency was significant only in grade 3. Once again, there is a shift as students' literacy skills develop. That is, first graders are more reliant on accuracy because their word reading fluency is still developing (and continues to do so for several more years). 


\section{Does Vocabulary Influence Both Word Recognition and Listening Comprehension in a Model Predicting Reading Comprehension?}

As shown in Figure 3, the third theoretical model hypothesizes that (a) vocabulary influences both word recognition and listening comprehension, (b) which in turn each influences reading comprehension. The purposes of testing this theoretical model were to determine (a) what the indirect effects of vocabulary are on reading comprehension and, (b) in a subsequent model, whether there is a direct effect of vocabulary on reading comprehension. In the indirect effects model (see Table 5), all of the factor loadings and structure coefficients were significantly different from zero $(p<.05)$ and in the expected direction (i.e., positive) for every grade. Model fit was also acceptable for each grade. Of particular interest are the structure coefficients across the grades. As previously shown in the word recognition model, in grade 1, word recognition had a much stronger influence on reading comprehension than did listening comprehension. As before, in grades 2 and 3, listening comprehension had a much stronger influence on reading comprehension than word recognition. Vocabulary had a strong effect on both word recognition and listening comprehension, which was somewhat stronger for listening comprehension than for word recognition at every grade.

In the direct effect model, although the specific results are not shown here, the direct effect of vocabulary on reading comprehension was not significant for any grade (i.e., the direct effect was approximately zero), and the fit of this model significantly deteriorated from the indirect effects model. Thus, we see evidence that the influence of vocabulary on reading comprehension is only an indirect effect through both word recognition and listening comprehension. 


\section{Discussion}

The simple view of reading describes reading comprehension as the product of word recognition and listening comprehension. Over the past three decades, considerable evidence has supported this framework for the study of reading development and the diagnosis of reading difficulties (e.g., Aaron, Joshi, \& Williams, 1999; Catts et al., 2003; Hoover \& Gough, 1990). In this study, we asked, generally, whether the simple view is too simple to explain the complexities of reading comprehension in the early years of formal education. Our response to this question is yes. Our study has many notable strengths, including the comparison of consecutive age groups, the use of multiple measures of each construct in our age-appropriate assessment battery, and our hypothesis-driven approach to model fitting. Using a cross-sectional sample of students in grades 1,2 , and 3 , we confirmed the basic premise of the simple view using a thorough, developmentally appropriate test battery: Individual differences in reading comprehension were explained by a student's ability to read words and comprehend language. Critically, our use of multiple measures provided a thorough and comprehensive assessment of each construct, and together, word recognition and listening comprehension explained approximately $90 \%$ of the variance in reading comprehension at each grade. Clearly, our data demonstrate that the basic model of the simple view of reading provides a good estimation of reading ability in these grades.

However, our findings also revealed important developmental nuances that build on the basic model: (a) Listening comprehension influences reading comprehension during the earliest stages of reading development; (b) the transition point at which listening comprehension becomes more prominent occurs early, around grade 2; (c) word recognition is best measured by word reading accuracy in the early grades and word reading fluency in the later grades; and (d) 
vocabulary skills affect reading comprehension indirectly through both word recognition and listening comprehension. Thus, our analyses provide a more comprehensive view of reading development, the implications of which we subsequently discuss.

\section{The Influence of Listening Comprehension on Reading Comprehension Is Evident Early and Increases Over Time}

Our finding of a key role for listening comprehension in the earliest stages of reading comprehension is supported by independent evidence of distinct factors representing the foundations of word recognition and listening comprehension in 4-6-year-olds (Kendeou, Savage, \& van den Broek, 2009). A few key studies have shown that word recognition explains a greater proportion of variation in reading comprehension in the early grades compared with listening comprehension, which contributes more to reading comprehension in the later grades (Catts et al., 2005; Garcia \& Cain, 2014; Oakhill \& Cain, 2012). Our study adds to these findings by pinpointing the grade at which this shift occurs, thus extending our understanding of the diachronic change predicted by the simple view.

Using structural equation modeling, we determined that word recognition began to contribute less variance to reading comprehension as early as grade 2 , when listening comprehension began to account more for individual differences in reading comprehension. There are several likely reasons for this shift. First, as subsequently discussed in more detail, word recognition skills are more automatic in older readers, thus enabling listening comprehension to play a greater role in the prediction of reading comprehension. Future research with more transparent orthographies will determine how early this shift is seen for readers of these languages who typically acquire fluent word recognition more easily. 
Second, we need to consider change in instructional focus and text complexity. At the onset of formal literacy instruction, a key aim is to teach students to read words. With this goal in mind, early texts include basic vocabulary, grammar, and discourse structures that provide practice in reading with a core vocabulary of easily decodable words. Our data show that in grade 2, a shift occurs in which individual differences in reading comprehension are more strongly related to a student's listening comprehension than his or her word recognition. It may be that the student's basic word reading abilities bootstrap him or her into more complex texts that, to comprehend, rely on robust listening comprehension skills. Thus, the simple view of reading could be expanded to describe important developmental changes in early reading comprehension.

These findings have ramifications for the diagnosis of and intervention for poor readers. Catts et al. (2003) used the simple view to categorize poor readers in a longitudinal sample of students tested in grades $\mathrm{K}, 2$, and 4. The researchers found that students' word recognition and listening comprehension skills were relatively stable from second to fourth grades but that listening comprehension difficulties, as a direct associate of reading comprehension, increased between grades 2 and 4 . The increasing influence of listening comprehension to reading comprehension means that the impact of listening comprehension deficits on poor reading comprehension will result in late-emerging, but long-standing, poor comprehenders (Catts, Compton, Tomblin, \& Bridges, 2012). We did not set out to test the prediction of different forms of reading disability, specifically students whose problems lie at either the word level (dyslexia), comprehension level (hyperlexia), or both (Gough \& Tunmer, 1986). However, we anticipate that these reader types exist in our sample. The findings of Catts et al. (2012) and these current analyses suggest that for diagnostic purposes, listening comprehension should be included in the 
assessment for reading difficulties. Such practice will enable intervention to target the specific skill weakness: word reading, text comprehension, or both.

These findings also have implications for instruction and, in particular, recent changes in the literacy targets in both the United States and the United Kingdom. Although a primary task of early formal education is to teach students to read words, time would be well spent also increasing listening comprehension skills to improve reading comprehension long term as these become an increasingly dominant force in reading for meaning. The Common Core State Standards (National Governors Association Center for Best Practices \& Council of Chief State School Officers, 2010) and the revised U.K. National Curriculum for English (Department for Education, 2014) emphasize the need for students to develop comprehension through experiences of a wide variety of genres for a range of purposes. This enables students to build knowledge through reading and to acquire and develop the skills needed to succeed not only in school but also in further education and employment. Our findings are in line with views that listening comprehension, as a valid and strong predictor of reading comprehension, can be the vehicle, for both young beginner readers and those who continue to struggle, to acquire ageappropriate word recognition skills to access and learn how to process these more challenging materials to develop key comprehension and critical thinking skills.

\section{Word Recognition Is Best Measured by Word Reading Fluency, not Word Reading Accuracy, in Later Grades}

Studies of the simple view of reading have measured word recognition in varied ways. Some have measured word recognition with single-word reading accuracy (Kershaw \& Schatschneider, 2012; Protopapas et al., 2012), and others have quantified word recognition through word reading in connected text (Adlof et al., 2006; Høien-Tengesdal \& Høien, 2012; Kershaw \& 
Schatschneider, 2012), whereas another approach has been to include the rate or ease with which single words or connected prose is read aloud (Adlof et al., 2006; Høien-Tengesdal \& Høien, 2012; Kershaw \& Schatschneider, 2012), Our objective was to determine whether word recognition was best characterized in the simple view by word recognition accuracy, word recognition fluency, or both. We found that both were separable constructs in our sample of students learning English orthography in grades 1-3. This finding is in line with Protopapas et al.'s study of young Greek readers (although in contrast with Adlof et al.'s study of young U.S. readers). Further, we determined that the nature of the relation between word recognition and reading comprehension changes over time. In grades 1 and 2, individual differences in word recognition were best quantified by accuracy measures. In contrast, for third graders, word reading fluency explained individual differences in comprehension, not word reading accuracy.

The convergence between our findings with an English-speaking sample and those of Protopapas et al. (2012) with a Greek-speaking sample (as well as convergence with the slightly older sample studied by Silverman et al., 2013) suggest that the separability of accuracy and fluency is not language dependent. However, our finding that accuracy and fluency were separable constructs is at odds with the study by Adlof et al. (2006) that included a similar battery of word recognition measures but did not identify fluency as separable from word recognition accuracy. One possible reason for this discrepancy is that Adlof et al.'s measures of reading fluency for connected text and word reading accuracy involved the same written materials, which will overestimate the association of the two measures. In our study, fluency and reading comprehension were assessed with separate stimuli. In addition, there was some indication that in Adlof et al.'s sample, fluency was tapping an additional construct, such as 
processing speed, because a substantial proportion of readers with poor fluency also had poor listening comprehension.

Our finding that a different measure of word recognition was the best predictor of reading comprehension at different grades is not wholly consistent with the simple view of reading and clearly suggests that a more nuanced model of reading development is required. There are several reasons for the change in influence of word reading accuracy and fluency across development. First, this may be explained by considering the changing nature of word recognition in the early grades. When students are first learning to read words, word reading is slow and more error prone. Thus, a measure of accuracy alone would be sufficient to capture variance. Later in development, fluency would become a more sensitive indicator of word recognition skills, when accuracy is easily achieved by most students and words can be read from memory (e.g., Ehri, 2014). This reasoning is supported by research on word recognition in languages with transparent orthographies, which have a direct relation between graphemes and phonemes (the letters and the sounds in the spoken language that they represent). For such languages, accuracy is achieved quickly, and measures that assess fluency have a greater influence on reading outcomes early on (Florit \& Cain, 2011). Thus, the relative influence of these two aspects of word recognition may be language dependent, particularly in young readers. Another possibility for the shift to reading fluency in predicting reading comprehension in grade 3 may be related to our inclusion of a measure of fluency for connected text. We note that performance on this measure was above average (Hasbrouck \& Tindal, 2006), but it was in line with the slightly above-average standardized scores for vocabulary (PPVT-4) and decoding (TOWRE-2; means $=98-109$ ). Words in context are typically read faster than words in isolation because word recognition can be facilitated through semantic activation when in context 
(Jenkins, Fuchs, van den Broek, Espin, \& Deno, 2003). For this reason, fluency may be a better metric of reading comprehension in grade 3. However, contextual facilitation for word reading is typically stronger for poorer readers than better or older readers, who have superior decoding ability and faster and more automatic sight word reading skills (Nation \& Snowling, 1998; Stanovich \& West, 1979). Critically, we are concerned with automaticity or efficiency of retrieval of phonological and semantic presentations of words, not simply the ability to read text faster. As noted in our introduction, broader definitions of fluency include prosody or the expression with which text is read aloud. Such definitions provide a theoretical link between reading fluency and reading comprehension (Kuhn et al., 2010) and should be adopted in future research to test the role of fluency in the simple view further.

Our results demonstrate the need to better represent developmental changes within the construct of word recognition as related to reading comprehension in the simple view of reading. Clearly, there is a complex relation between fluency of word reading in context and reading comprehension skill. Our findings are limited because we were not able to identify the precise causal mechanism for the fluency-comprehension relationship. A priority of future research should be to directly test whether the nature of the assessment of reading fluency influences the strength of the relation between word recognition and reading comprehension and whether this differs between good and poor readers.

\section{Vocabulary Skills Indirectly Affect Reading Comprehension Through Both Word Recognition and Listening Comprehension}

It is well established that individual differences in vocabulary predict listening comprehension skills (Nation \& Snowling, 2004; Ouellette \& Beers, 2010). Studies have also shown a link between vocabulary abilities and individual differences in word reading (Mitchell \& Brady, 
2013; Nation \& Snowling, 2004; Ouellette, 2006). Using a latent construct approach, Tunmer and Chapman (2012) found that the construct of listening comprehension fed into reading comprehension directly, and also indirectly through its influence on word recognition. Although they did not test whether vocabulary was the specific basis for this mediating link, our results support that hypothesis. We found that vocabulary indirectly predicted reading comprehension: It influenced listening comprehension and word recognition, which in turn predicted reading comprehension. Moreover, our results showed that the influence of vocabulary was stronger for listening comprehension than word recognition.

Students' vocabulary knowledge differs widely upon beginning formal literacy instruction (Hart \& Risley, 1995). Our results demonstrate how vocabulary knowledge influences reading development in beginner readers and, therefore, how it fits into the simple view. Vocabulary knowledge is related to word recognition in at least two ways, because it reflects consolidated knowledge about familiar individual word forms and because a wide vocabulary supports the processing of unfamiliar words through strategies such as reading by analogy (Ehri, 2014). In addition, vocabulary knowledge might be related to reading ability because it reflects students' general language competence, which will influence reading development (Nation \& Snowling, 2004). Our data suggest a stronger influence of vocabulary in the prediction of listening comprehension than for word recognition (see also Nation \& Snowling, 2004) but does not identify a direct relation to reading comprehension. This model confirms the important role of word knowledge for sentence- and text-level processing, which is supported by other work that demonstrates a critical role for higher level language skills in early listening and reading comprehension development (Florit, Roch, \& Levorato, 2011; Kendeou, 
van den Broek, et al., 2009; Lepola, Lynch, Laakkonen, Silvén, \& Niemi, 2012; Oakhill \& Cain, 2012).

Vocabulary may be important for comprehension because words form the basis of sentences and longer units of text and also because it specifically enables integration and inference making (Cain \& Oakhill, in press; Kintsch \& Rawson, 2005; Perfetti \& Stafura, 2014). However, other forms of knowledge enable successful comprehension as well. For example, knowledge about text structure can influence comprehension by providing a framework (Cain, 1996), topic knowledge supports better comprehension of text (Compton, Miller, Elleman, \& Steacy, 2014), and instruction in reading strategies improves reading comprehension (Rosenshine \& Meister, 1994). A broader range of knowledge and its influence on reading comprehension is a target for future research.

\section{Strengths and Limitations}

A strength of our study was the use of multiple measures to provide a comprehensive assessment of each construct. This is one reason why our models typically explained around $90 \%$ of the variance in reading comprehension. With a single measure of a given construct, there is measurement error in the system due to reliability and/or validity issues. Using multiple measures of a construct in a latent variable isolates and takes measurement error into account. As a result, the relations among the latent variables are likely to have more explained variance. However, we note that there remains around $10 \%$ of unexplained variance in the system, which is likely due to factors such as instruction, individual differences among the participants, and other literacy constructs not included in our model.

We used a range of measures of the decoding construct in the simple view and found that accuracy and fluency measures were separable. A recent meta-analysis supports this finding and 
further demonstrates that other test characteristics influence the strength of the relation between word recognition and reading comprehension (see Garcia \& Cain, 2014, for a summary of different assessments). Thus, based on our own work and the work of our colleagues in the field, we do not believe that a single measure of word recognition, listening comprehension, or reading comprehension is best. Reading is complex, and different assessments tap different things. This is illustrated in a recent study that examined the identification of students with comprehension difficulties across a range of standardized tests (Keenan \& Meenan, 2014): Notably, not all assessments identified the same students each time. Together, these findings lead us to conclude that researchers and practitioners should strive to take multiple measures of target constructs.

In relation to the complexity of reading, we note that we did not include other assessments of the broader language and cognitive skills that might underpin both word recognition and reading comprehension. Other researchers have found that broader language skills (e.g., semantic, morphological, grammatical; Catts et al., 2006; Nation \& Snowling, 2004; Tong, Deacon, \& Cain, 2014) and also cognitive skills (e.g., working memory, executive functions; Cain, Oakhill, \& Bryant, 2004; Locascio, Mahone, Eason, \& Cutting, 2010) influence reading comprehension outcomes. We did not include independent assessments of these skills in our analysis for two reasons. First, we focused on the examination of the influence of two additional components - fluency and vocabulary — about which there has been significant recent debate. Second, it is likely that all of these language and cognitive processes contribute to both reading and listening comprehension. As a result, we believe that they all, in part, underpin the listening comprehension construct in our model.

Finally, it is worth noting that our results should not be taken to suggest that word reading is not a continuing source of difficulty for some readers past grade 2 : A proportion of 
poor readers have either specific difficulties with word reading (i.e., dyslexia) or difficulties with both decoding and language comprehension that continue across the lifespan. These individuals will benefit from support beyond the early grades to develop their word reading skills.

\section{Conclusions}

The simple view of reading explains the complex phenomenon of reading comprehension by decomposing it into word recognition and listening comprehension. Our results support this broad framework, but our answer to the question posed in our title is no. In line with other research, our findings show that reading development is not so simple and provide us with a more comprehensive view of early reading development. The simple view should be elaborated to include developmental changes in its subcomponents, a more nuanced view of word recognition, and indirect effects of vocabulary. This more fine-grained view of reading development has diagnostic and instructional ramifications for improving reading pedagogy. 


\section{Notes}

This paper was prepared by a task force of the Language and Reading Research Consortium (LARRC) consisting of Kate Cain (convener), Hugh Catts, Tiffany Hogan, and Richard Lomax. LARRC project sites and investigators are as follows:

- Ohio State University (Columbus, OH): Laura M. Justice (site principal investigator; SPI), Richard Lomax, Ann O'Connell, Jill Pentimonti, Stephen A. Petrill, ${ }^{1}$ and Shayne B. Piasta

- Arizona State University (Tempe, AZ): Shelley Gray (SPI) and Maria Adelaida Restrepo

- Lancaster University (Lancaster, UK): Kate Cain (SPI)

- University of Kansas (Lawrence, KS): Hugh Catts ${ }^{2}$ (SPI), Mindy Bridges, and Diane Nielsen

- University of Nebraska-Lincoln (Lincoln, NE): Tiffany Hogan ${ }^{3}$ (SPI), Jim Bovaird, and J. Ron Nelson ${ }^{4}$

1. Petrill was a LARRC coinvestigator from 2010 to 2013.

2. Catts is now at Florida State University (Tallahassee, FL).

3. Hogan is now at the MGH Institute of Health Professions (Boston, MA).

4. Nelson was a LARRC coinvestigator from 2010 to 2012.

This work was supported by grant R305F 100002 of the Institute of Education Sciences's Reading for Understanding Initiative. The views presented in this work do not represent those of the federal government, nor do they endorse any products or findings presented herein. We are deeply grateful to the numerous staff, research associates, school administrators, teachers, students, and families who participated. Key personnel at study sites include Garey Berry, Beau Bevens, Jennifer Bostic, Shara Brinkley, Lori Chleborad, Dawn Davis, Michel Eltschinger, Tamarine Foreman, Rashaun Geter, Sara Gilliam, Miki Herman, Trudy Kuo, Gustavo Lujan, Carol Mesa, Denise Meyer, Maria Moratto, Marcie Mutters, Trevor Rey, and Stephanie 
Williams. We would like to thank Gloria Yeomans-Maldonado and Jill Pentimonti in particular for their help with the reliability analyses.

Correspondence concerning this work should be sent to Kate Cain at

k.cain@lancaster.ac.uk. 


\section{References}

Aaron, P. G., Joshi, M., \& Williams, K. A. (1999). Not all reading disabilities are alike. Journal of Learning Disabilities, 32, 120-137.

Adlof, S.M., Catts, H.W., \& Little, T.D. (2006). Should the simple view of reading include a fluency component? Reading and Writing, 19(9), 933-958. doi:10.1007/s11145-006$9024-\mathrm{z}$

Arcand, M.S., Dion, E., Lemire-Théberge, L., Guay, M.H., Barrette, A., Gagnon, V., ... Fuchs, D. (2014). Segmenting texts into meaningful word groups: Beginning readers' prosody and comprehension. Scientific Studies of Reading, 18(3), 208-223.

doi:10.1080/10888438.2013.864658

Braze, D., Tabor, W., Shankweiler, D.P., \& Mencl, W.E. (2007). Speaking up for vocabulary: Reading skill differences in young adults. Journal of Learning Disabilities, 40(3), 226243. doi:10.1177/00222194070400030401

Cain, K. (1996). Story knowledge and comprehension skill. In C. Cornoldi \& J. Oakhill (Eds.), Reading comprehension difficulties: Processes and remediation (pp. 167-192). Mahwah, NJ: Erlbaum.

Cain, K., \& Oakhill, J. (2006a). Assessment matters: Issues in the measurement of reading comprehension. British Journal of Educational Psychology, 76(4), 697-708. doi:10.1348/000709905X69807

Cain, K., \& Oakhill, J. (2006b). Profiles of children with specific reading comprehension difficulties. British Journal of Educational Psychology, 76(4), 683-696. doi:10.1348/000709905X67610 
Cain, K., \& Oakhill, J. (in press). Reading comprehension and vocabulary: Is vocabulary more important for some aspects of comprehension? L'Année Psychologique.

Cain, K., Oakhill, J.V., \& Bryant, P.E. (2004). Children's reading comprehension ability: Concurrent prediction by working memory, verbal ability, and component skills. Journal of Educational Psychology, 96(1), 31-42. doi:10.1037/0022-0663.96.1.31

Catts, H.W., Adlof, S.M., \& Weismer, S.E. (2006). Language deficits in poor comprehenders: A case for the simple view of reading. Journal of Speech, Language, and Hearing Research, 49(2), 278-293. doi:10.1044/1092-4388(2006/023)

Catts, H.W., Compton, D.L., Tomblin, J.B., \& Bridges, M.S. (2012). Prevalence and nature of late-emerging poor readers. Journal of Educational Psychology, 104(1), 166-181. doi:10.1037/a0025323

Catts, H.W., Hogan, T.P., \& Adlof, S.M. (2005). Developmental changes in reading and reading disabilities. In H.W. Catts \& A.G. Kamhi (Eds.), The connections between language and reading disabilities (pp. 25-40). Mahwah, NJ: Erlbaum.

Catts, H.W., Hogan, T.P., \& Fey, M.E. (2003). Subgrouping poor readers on the basis of individual differences in reading-related abilities. Journal of Learning Disabilities, 36(2), 151-164. doi:10.1177/002221940303600208

Compton, D.L., Miller, A.C., Elleman, A.M., \& Steacy, L.M. (2014). Have we forsaken reading theory in the name of "quick fix" interventions for children with reading disability? Scientific Studies of Reading, 18(1), 55-73. doi:10.1080/10888438.2013.836200

Cunningham, A.E., Stanovich, K.E., \& Wilson, M.R. (1990). Cognitive variation in adult college students differing in reading ability. In T.H. Carr \& B.A. Levy (Eds.), Reading and its development: Component skills approaches (pp. 129-159). San Diego, CA: Academic. 
Cutting, L.E., \& Scarborough, H.S. (2006). Prediction of reading comprehension: Relative contributions of word recognition, language proficiency, and other cognitive skills can depend on how comprehension is measured. Scientific Studies of Reading, 10(3), 277299. doi:10.1207/s1532799xssr1003_5

de Jong, P.F., \& van der Leij, A. (2002). Effects of phonological abilities and linguistic comprehension on the development of reading. Scientific Studies of Reading, 6(1), 51-77. doi:10.1207/S1532799XSSR0601_03

Department for Education (2014). National Curriculum in England: English programmes of Study, from https://www.gov.uk/government/publications/national-curriculum-in-englandenglish-programmes-of-study/national-curriculum-in-england-english-programmes-of-study Dunn, L. M., \& Dunn, D. M. (2007). Peabody Picture Vocabulary Test--Fourth Edition: Pearson Assessment.

Ehri, L.C. (2014). Orthographic mapping in the acquisition of sight word reading, spelling memory, and vocabulary learning. Scientific Studies of Reading, 18(1), 5-21. doi:10.1080/10888438.2013.819356

Florit, E., \& Cain, K. (2011). The simple view of reading: Is it valid for different types of alphabetic orthographies? Educational Psychology Review, 23(4), 553-576. doi:10.1007/s10648-011-9175-6

Florit, E., Roch, M., \& Levorato, M.C. (2011). Listening text comprehension of explicit and implicit information in preschoolers: The role of verbal and inferential skills. Discourse Processes, 48(2), 119-138. doi:10.1080/0163853X.2010.494244 
Fuchs, L.S., Fuchs, D., Hosp, K.K., \& Jenkins, J.R. (2001). Oral reading fluency as an indicator of reading competence: A theoretical, empirical, and historical analysis. Scientific Studies of Reading, 5(3), 239-256. doi:10.1207/S1532799XSSR0503_3

Garcia, J.R., \& Cain, K. (2014). Decoding and reading comprehension: A meta-analysis to identify which reader and assessment characteristics influence the strength of the relationship in English. Review of Educational Research, 84(1), 74-111. doi:10.3102/0034654313499616

Gillam, R. B., \& Pearson, N. A. (2004). Test of Narrative Language-Receptive. (PRO-ED, 8700 Shoal Creek Blvd., Austin, TX 78757-6897): Pearson.

Gough, P.B., Hoover, W.A., \& Peterson, C.L. (1996). Some observations on a simple view of reading. In C. Cornoldi \& J. Oakhill (Eds.), Reading comprehension difficulties: Processes and interventions (pp. 1-13). Mahwah, NJ: Erlbaum.

Gough, P.B., \& Tunmer, W.E. (1986). Decoding, reading and reading disability. Remedial and Special Education, 7(1), 6-10. doi:10.1177/074193258600700104

Hancock, G.R., \& Mueller, R.O. (2011). The reliability paradox in assessing structural relations within covariance structure models. Educational and Psychological Measurement, 71(2), 306-324. doi:10.1177/0013164410384856

Hart, B., \& Risley, T. (1995). Meaningful differences in the everyday experience of young American children. Baltimore, MD: Paul H. Brookes.

Hasbrouck, J., \& Tindal, G.A. (2006). Oral reading fluency norms: A valuable assessment tool for reading teachers. The Reading Teacher, 59(7), 636-644. doi:10.1598/RT.59.7.3 
Høien-Tengesdal, I., \& Høien, T. (2012). The reading efficiency model: An extension of the componential model of reading. Journal of Learning Disabilities, 45(5), 467-479. doi:10.1177/0022219411432688

Hoover, W.A., \& Gough, P.B. (1990). The simple view of reading. Reading and Writing, 2(2), 127-160. doi:10.1007/BF00401799

Jenkins, J.R., Fuchs, L.S., van den Broek, P., Espin, C., \& Deno, S.L. (2003). Sources of individual differences in reading comprehension and reading fluency. Journal of Educational Psychology, 95(4), 719-729. doi:10.1037/0022-0663.95.4.719

Johnston, T.C., \& Kirby, J.R. (2006). The contribution of naming speed to the simple view of reading. Reading and Writing, 19(4), 339-361. doi:10.1007/s11145-005-4644-2

Joreskog, K.G., \& Sorbom, D. (2012). LISREL 9.1. Lincolnwood, IL: Scientific Software International.

Joshi, R.M., \& Aaron, P.G. (2000). The component model of reading: Simple view of reading made a little more complex. Reading Psychology, 21(2), 85-97. doi:10.1080/02702710050084428

Keenan, J.M., \& Betjemann, R.S. (2006). Comprehending the Gray Oral Reading Test without reading it: Why comprehension tests should not include passage-independent items. Scientific Studies of Reading, 10(4), 363-380. doi:10.1207/s1532799xssr1004_2

Keenan, J.M., Betjemann, R.S., \& Olson, R.K. (2008). Reading comprehension tests vary in the skills they assess: Differential dependence on decoding and oral comprehension. Scientific Studies of Reading, 12(3), 281-300. doi:10.1080/10888430802132279 
Keenan, J.M., \& Meenan, C.E. (2014). Test differences in diagnosing reading comprehension deficits. Journal of Learning Disabilities, 47(2), 125-135. doi:10.1177/0022219412439326

Kendeou, P., Savage, R., \& van den Broek, P. (2009). Revisiting the simple view of reading. British Journal of Educational Psychology, 79(2), 353-370. doi:10.1348/978185408X369020

Kendeou, P., van den Broek, P., White, M., \& Lynch, J.S. (2009). Predicting reading comprehension in early elementary school: The independent contributions of oral language and decoding skills. Journal of Educational Psychology, 101(4), 765-778. doi:10.1037/a0015956

Kershaw, S., \& Schatschneider, C. (2012). A latent variable approach to the simple view of reading. Reading and Writing, 25(2), 433-464. doi:10.1007/s11145-010-9278-3

Kintsch, W., \& Rawson, K.A. (2005). Comprehension. In M.J. Snowling \& C. Hulme (Eds.), The science of reading: A handbook (pp. 211-226). Malden, MA: Blackwell. doi:10.1002/9780470757642.ch12

Kirby, J., \& Savage, R. (2008). Can the simple view deal with the complexities of reading? Literacy, 42(2), 75-82. doi:10.1111/j.1741-4369.2008.00487.x

Kuhn, M.R., Schwanenflugel, P.J., \& Meisinger, E.B. (2010). Aligning theory and assessment of reading fluency: Automaticity, prosody, and definitions of fluency. Reading Research Quarterly, 45(2), 230-251. doi:10.1598/RRQ.45.2.4

Lepola, J., Lynch, J.S., Laakkonen, E., Silvén, M., \& Niemi, P. (2012). The role of inference making and other language skills in the development of narrative listening 
comprehension in 4-6-year-old children. Reading Research Quarterly, 47(3), 259-282. doi:10.1002/RRQ.020

Leslie, L., \& Caldwell, J.S. (2010). Qualitative Reading Inventory (5th ed.). Boston, MA: Pearson.

Locascio, G., Mahone, E.M., Eason, S., \& Cutting, L.E. (2010). Executive dysfunction among children with reading comprehension deficits. Journal of Learning Disabilities, 43(5), 441-454. doi:10.1177/0022219409355476

MacGinitie, W. H., MacGinitie, R. K., Maria, K., \& Dreyer, L. G. (2000). Gates-MacGinitie Reading Tests (4 ed.). Itasca, Illinois Riverside Publishing.

Megherbi, H., \& Ehrlich, M.F. (2005). Language impairment in less skilled comprehenders: The on-line processing of anaphoric pronouns in a listening situation. Reading and Writing, 18(7-9), 715-753. doi:10.1007/s11145-005-8131-6

Megherbi, H., Seigneuric, A., \& Ehrlich, M.-F. (2006). Reading comprehension in French 1st and 2nd grade children: Contribution of decoding and language comprehension. European Journal of Psychology of Education, 21(2), 135-147. doi:10.1007/BF03173573

Mitchell, A.M., \& Brady, S.A. (2013). The effect of vocabulary knowledge on novel word identification. Annals of Dyslexia, 63(3/4), 201-216. doi:10.1007/s11881-013-0080-1

Muter, V., Hulme, C., Snowling, M., \& Stevenson, J. (2004). Phonemes, rimes, vocabulary, and grammatical skills as foundations of early reading development: Evidence from a longitudinal study. Developmental Psychology, 40(5), 665-681. doi:10.1037/00121649.40.5.665 
Nation, K., \& Snowling, M. (1997). Assessing reading difficulties: The validity and utility of current measures of reading skill. British Journal of Educational Psychology, 67(3), 359370. doi:10.1111/j.2044-8279.1997.tb01250.x

Nation, K., \& Snowling, M.J. (1998). Individual differences in contextual facilitation: Evidence from dyslexia and poor reading comprehension. Child Development, 69(4), 996-1011. doi:10.1111/j.1467-8624.1998.tb06157.x

Nation, K., \& Snowling, M.J. (2004). Beyond phonological skills: Broader language skills contribute to the development of reading. Journal of Research in Reading, 27(4), 342356. doi:10.1111/j.1467-9817.2004.00238.xNational Governors Association Center for Best Practices \& Council of Chief State School Officers. (2010). Common Core State Standards for English language arts and literacy in history/social studies, science, and technical subjects. Washington, DC: Authors.

Oakhill, J., \& Cain, K. (2012). The precursors of reading comprehension and word reading in young readers: Evidence from a four-year longitudinal study. Scientific Studies of Reading, 16(2), 91-121. doi:10.1080/10888438.2010.529219

Oakhill, J., Cain, K., \& Bryant, P.E. (2003). The dissociation of word reading and text comprehension: Evidence from component skills. Language and Cognitive Processes, 18(4), 443-468. doi:10.1080/01690960344000008

Olson, R.K., Keenan, J.M., Byrne, B., \& Samuelsson, S. (2014). Why do children differ in their development of reading and related skills? Scientific Studies of Reading, 18(1), 38-54. doi:10.1080/10888438.2013.800521 
Ouellette, G.P. (2006). What's meaning got to do with it: The role of vocabulary in word reading and reading comprehension. Journal of Educational Psychology, 98(3), 554-566. doi:10.1037/0022-0663.98.3.554

Ouellette, G.P., \& Beers, A. (2010). A not-so-simple view of reading: How oral vocabulary and visual-word recognition complicate the story. Reading and Writing, 23(2), 189-208. doi:10.1007/s11145-008-9159-1

Pazzaglia, F., Cornoldi, C., \& Tressoldi, P.E. (1993). Learning to read: Evidence on the distinction between decoding and comprehension skills. European Journal of Psychology of Education, 8(3), 247-258. doi:10.1007/BF03174080

Perfetti, C.A. (2007). Reading ability: Lexical quality to comprehension. Scientific Studies of Reading, 11(4), 357-383. doi:10.1080/10888430701530730

Perfetti, C.A., \& Stafura, J. (2014). Reading comprehension: Including word knowledge in a theoretical framework. Scientific Studies of Reading, 18(1), 22-37. doi:10.1080/10888438.2013.827687

Protopapas, A., Simos, P.G., Sideridis, G.D., \& Mouzaki, A. (2012). The components of the simple view of reading: A confirmatory factor analysis. Reading Psychology, 33(3), 217 240. doi:10.1080/02702711.2010.507626

Ransby, M.J., \& Swanson, H.L. (2003). Reading comprehension skills of young adults with childhood diagnoses of dyslexia. Journal of Learning Disabilities, 36(6), 538-555. doi:10.1177/00222194030360060501

Rosenshine, B., \& Meister, C. (1994). Reciprocal teaching: A review of the research. Review of Educational Research, 64(4), 479-530. doi:10.3102/00346543064004479 
Schumacker, R.E., \& Lomax, R.G. (2010). A beginner's guide to structural equation modeling (3rd ed.). New York, NY: Routledge.

Semel, E., \& Wiig, E. (2006). Clinical Evaluation of Language Fundamentals: 4: Pearson Assessment.

Silverman, R.D., Speece, D.L., Harring, J.R., \& Ritchey, K.D. (2013). Fluency has a role in the simple view of reading. Scientific Studies of Reading, 17(2), 108-133.

doi:10.1080/10888438.2011.618153

Snow, C.E. (2002). Reading for understanding: Toward an R\&D program in reading comprehension. Santa Monica, CA: RAND.

Stanovich, K.E., \& West, R.F. (1979). Mechanisms of sentence context effects in reading: Automatic activation and conscious attention. Memory \& Cognition, 7(2), 77-85. doi:10.3758/BF03197588

State of Florida, Department of Education, Florida Center for Reading Research. (2009). Florida Assessment for Instruction in Reading: Oral Reading Fluency. Tallahassee: Author.

Tilstra, J., McMaster, K.L., van den Broek, P., Kendeou, P., \& Rapp, D.N. (2009). Simple but complex: Components of the simple view of reading across grade levels. Journal of Research in Reading, 32(4), 383-401. doi:10.1111/j.1467-9817.2009.01401.x

Tong, X., Deacon, S.H., \& Cain, K. (2014). Morphological and syntactic awareness in poor comprehenders: Another piece of the puzzle. Journal of Learning Disabilities, 47(1), 22 33. doi:10.1177/0022219413509971

Torgesen, J. K., Wagner, R. K., \& Rashotte, C. A. (2011). Test of Word Reading Efficiency (TOWRE) (2 ed.): Psychological Corporation. 
Torppa, M., Tolvanen, A., Poikkeus, A.-M., Leskinene, E., \& Lyytinen, H. (2007). Reading development subtypes and their early characteristics. Annals of Dyslexia, 57(1), 3-32. doi:10.1007/s11881-007-0003-0

Tunmer, W.E., \& Chapman, J.W. (2012). The simple view of reading redux: Vocabulary knowledge and the independent components hypothesis. Journal of Learning Disabilities, 45(5), 453-466. doi:10.1177/0022219411432685

Vellutino, F.R., Tunmer, W.E., Jaccard, J.J., \& Chen, R. (2007). Components of reading ability: Multivariate evidence for a convergent skill model of reading development. Scientific Studies of Reading, 11(1), 3-32.

Wagner, R.K., Torgesen, J.K., Rashotte, C.A., \& Pearson, N. (2010). Test of Silent Reading Efficiency and Comprehension. Austin, TX: Pro-Ed.

Wolf, M., \& Katzir-Cohen, T. (2001). Reading fluency and its intervention. Scientific Studies of Reading, 5, 211-239.

Woodcock, R. W. (1997). Woodcock Reading Mastery Test-Revised/Normative Update (WRMT-R/NU). Bloomington, MN: American Guidance Service/ Pearson Assessments.

Young, A., \& Bowers, P.G. (1995). Individual difference and text difficulty determinants of reading fluency and expressiveness. Journal of Experimental Child Psychology, 60(3), 428-454. doi:10.1006/jecp.1995.1048

Submitted May 5, 2014

Final revision received November 13, 2014

Accepted December 10, 2014 


\section{Online appendix}

First-Grade Correlation Matrix

\begin{tabular}{|l|c|c|c|c|c|c|c|c|c|c|c|c|c|}
\hline & $\mathbf{1}$ & $\mathbf{2}$ & $\mathbf{3}$ & $\mathbf{4}$ & $\mathbf{5}$ & $\mathbf{6}$ & $\mathbf{7}$ & $\mathbf{8}$ & $\mathbf{9}$ & $\mathbf{1 0}$ & $\mathbf{1 1}$ & $\mathbf{1 2}$ & $\mathbf{1 3}$ \\
\hline 1. RC & - & & & & & & & & & & & & \\
\hline 2. PC & .752 & - & & & & & & & & & & & \\
\hline 3. RCM & .564 & .551 & - & & & & & & & & & & \\
\hline 4. Word ID & .772 & .882 & .553 & - & & & & & & & & & \\
\hline 5. Word attack & .582 & .720 & .404 & .828 & - & & & & & & & & \\
\hline 6. SWE & .735 & .826 & .522 & .882 & .682 & - & & & & & & & \\
\hline 7. PDE & .560 & .703 & .394 & .808 & .734 & .762 & - & & & & & & \\
\hline 8. ORF & .719 & .817 & .457 & .872 & .687 & .873 & .801 & - & & & & & \\
\hline 9. TNL-R & .458 & .511 & .567 & .493 & .414 & .460 & .440 & .510 & - & & & & \\
\hline 10. USP & .277 & .257 & .214 & .222 & .208 & .244 & .156 & .258 & .340 & - & & & \\
\hline 11. LCM & .493 & .442 & .539 & .433 & .277 & .401 & .269 & .440 & .625 & .167 & - & & \\
\hline 12. PPVT-4 & .442 & .487 & .504 & .486 & .331 & .420 & .320 & .451 & .573 & .311 & .612 & - & \\
\hline 13. EVT-2 & .581 & .624 & .638 & .641 & .442 & .607 & .473 & .598 & .617 & .322 & .558 & .789 & - \\
\hline 14. CELF-4 WC & .450 & .364 & .398 & .372 & .359 & .365 & .323 & .405 & .368 & .195 & .341 & .346 & .441 \\
\hline
\end{tabular}

Note. CELF-4 WC = Clinical Evaluation of Language Fundamentals-Fourth Edition word classes; EVT-2 =

Expressive Vocabulary Test, second edition; LCM = Listening Comprehension Measure; ORF = Florida Assessment for Instruction in Reading: Oral Reading Fluency; PC = WRMT-R/NU passage comprehension subtest; PDE = Test of Word Reading Efficiency-Second Edition (TOWRE-2) phonemic decoding subtest; PPVT-4 = Peabody Picture Vocabulary Test, fourth edition; RC = Gates-MacGinitie reading comprehension subtest; $R C M=$ Reading Comprehension Measure; SWE = TOWRE-2 sight word subtest; TNL-R = Test of Narrative Language-Receptive; UP $=$ CELF-4 understanding spoken paragraphs subtest; Word attack $=$ Woodcock Reading Mastery Tests-Revised: Normative Update (WRMT-R/NU) word attack subtest; Word ID = WRMT-R/NU word identification subtest. 
Second-Grade Correlation Matrix

\begin{tabular}{|l|c|c|c|c|c|c|c|c|c|c|c|c|c|}
\hline & $\mathbf{1}$ & $\mathbf{2}$ & $\mathbf{3}$ & $\mathbf{4}$ & $\mathbf{5}$ & $\mathbf{6}$ & $\mathbf{7}$ & $\mathbf{8}$ & $\mathbf{9}$ & $\mathbf{1 0}$ & $\mathbf{1 1}$ & $\mathbf{1 2}$ & $\mathbf{1 3}$ \\
\hline 1. RC & - & & & & & & & & & & & & \\
\hline 2. PC & .703 & - & & & & & & & & & & & \\
\hline 3. RCM & .633 & .576 & - & & & & & & & & & & \\
\hline 4. Word ID & .636 & .744 & .491 & - & & & & & & & & & \\
\hline 5. Word attack & .489 & .635 & .383 & .805 & - & & & & & & & & \\
\hline 6. SWE & .493 & .565 & .298 & .653 & .515 & - & & & & & & & \\
\hline 7. PDE & .473 & .581 & .258 & .757 & .721 & .761 & - & & & & & & \\
\hline 8. ORF & .575 & .653 & .410 & .796 & .620 & .761 & .724 & - & & & & & \\
\hline 9. TNL-R & .509 & .507 & .542 & .480 & .300 & .267 & .271 & .425 & - & & & & \\
\hline 10. UP & .472 & .443 & .499 & .338 & .235 & .335 & .281 & .395 & .436 & - & & & \\
\hline 11. LCM & .548 & .501 & .642 & .426 & .348 & .231 & .242 & .366 & .582 & .490 & - & & \\
\hline 12. PPVT-4 & .578 & .544 & .604 & .450 & .376 & .239 & .221 & .344 & .564 & .491 & .632 & - & \\
\hline 13. EVT-2 & .516 & .533 & .492 & .504 & .464 & .237 & .250 & .401 & .551 & .454 & .526 & .761 & - \\
\hline 14. CELF-4 WC & .533 & .504 & .470 & .359 & .284 & .240 & .278 & .338 & .407 & .460 & .408 & .471 & .301 \\
\hline
\end{tabular}

Note. CELF-4 WC = Clinical Evaluation of Language Fundamentals-Fourth Edition word classes; EVT-2 = Expressive Vocabulary Test, second edition; LCM = Listening Comprehension Measure; ORF = Florida Assessment for Instruction in Reading: Oral Reading Fluency; PC = WRMT-R/NU passage comprehension subtest; PDE = Test of Word Reading Efficiency-Second Edition (TOWRE-2) phonemic decoding subtest; PPVT-4 = Peabody Picture Vocabulary Test, fourth edition; RC = Gates-MacGinitie reading comprehension subtest; RCM = Reading Comprehension Measure; SWE = TOWRE-2 sight word subtest; TNL-R = Test of Narrative Language-Receptive; UP = CELF-4 understanding spoken paragraphs subtest; Word attack $=$ Woodcock Reading Mastery Tests - Revised: Normative Update (WRMT-R/NU) word attack subtest; Word ID = WRMT-R/NU word identification subtest. 
Third-Grade Correlation Matrix

\begin{tabular}{|l|c|c|c|c|c|c|c|c|c|c|c|c|c|}
\hline & $\mathbf{1}$ & $\mathbf{2}$ & $\mathbf{3}$ & $\mathbf{4}$ & $\mathbf{5}$ & $\mathbf{6}$ & $\mathbf{7}$ & $\mathbf{8}$ & $\mathbf{9}$ & $\mathbf{1 0}$ & $\mathbf{1 1}$ & $\mathbf{1 2}$ & $\mathbf{1 3}$ \\
\hline 1. RC & - & & & & & & & & & & & & \\
\hline 2. PC & .722 & - & & & & & & & & & & & \\
\hline 3. RCM & .675 & .541 & - & & & & & & & & & & \\
\hline 4. Word ID & .642 & .727 & .524 & - & & & & & & & & & \\
\hline 5. Word attack & .425 & .601 & .320 & .764 & - & & & & & & & & \\
\hline 6. SWE & .521 & .568 & .514 & .725 & .529 & - & & & & & & & \\
\hline 7. PDE & .479 & .551 & .381 & .774 & .721 & .716 & - & & & & & & \\
\hline 8. ORF & .623 & .699 & .529 & .747 & .608 & .785 & .733 & - & & & & & \\
\hline 9. TNL-R & .509 & .409 & .446 & .352 & .317 & .274 & .302 & .356 & - & & & & \\
\hline 10. UP & .513 & .317 & .532 & .255 & .140 & .251 & .219 & .224 & .361 & - & & & \\
\hline 11. LCM & .652 & .450 & .521 & .366 & .267 & .299 & .274 & .298 & .531 & .593 & - & & \\
\hline 12. PPVT-4 & .586 & .495 & .546 & .537 & .364 & .362 & .426 & .472 & .481 & .418 & .572 & - & \\
\hline 13. EVT-2 & .612 & .539 & .550 & .583 & .397 & .418 & .355 & .487 & .461 & .414 & .525 & .702 & - \\
\hline 14. CELF-4 WC & .616 & .604 & .514 & .634 & .488 & .413 & .453 & .542 & .480 & .378 & .511 & .687 & .638 \\
\hline
\end{tabular}

Note. CELF-4 WC = Clinical Evaluation of Language Fundamentals-Fourth Edition word classes; EVT-2 = Expressive Vocabulary Test, second edition; LCM = Listening Comprehension Measure; ORF = Florida Assessment for Instruction in Reading: Oral Reading Fluency; PC = WRMT-R/NU passage comprehension subtest; PDE = Test of Word Reading Efficiency-Second Edition (TOWRE-2) phonemic decoding subtest; PPVT-4 = Peabody Picture Vocabulary Test, fourth edition; RC = Gates-MacGinitie reading comprehension subtest; RCM = Reading Comprehension Measure; SWE = TOWRE-2 sight word subtest; TNL-R = Test of Narrative Language-Receptive; UP = CELF-4 understanding spoken paragraphs subtest; Word attack $=$ Woodcock Reading Mastery Tests-Revised: Normative Update (WRMT-R/NU) word attack subtest; Word ID = WRMT-R/NU word identification subtest. 


\section{FIGURE 1}

\section{Simple View of Reading Models Across Grades 1-3}

Note. Standardized estimates from the structural model, where ".22 (.57) .60" represents the results for the first. second, and third grades, respectively. All paths are significantly different from zero $(p<.05)$.

\section{FIGURE 2}

\section{Word Reading Fluency and Word Reading Accuracy Model}

Note. Standardized estimates from the structural model, where ".24 (.57) .61" represents the results for the first, (second) and third grades, respectively. All paths are significantly different from zero $(p<.05)$, unless otherwise indicated by *.

\section{FIGURE 3}

\section{Vocabulary Model}

Note. Standardized estimates from the structural model, where ".83 (.93) .78" represents the results for the first, second, and third grades, respectively. All paths are significantly different from zero $(p<.05)$. 
TABLE 1

Selected Baseline Student Characteristics

\begin{tabular}{|l|c|c|c|}
\hline Characteristic & Grade 1 & Grade 2 & Grade 3 \\
\hline$N$ & 125 & 123 & 123 \\
\hline Age (baseline 2010) & $6.56(0.34)$ & $7.53(0.35)$ & $8.58(0.38)$ \\
\hline Family income (categorical) & & & \\
\hline$\bullet \%<\$ 40 \mathrm{~K}$ & 17.6 & 26.0 & 13.8 \\
\hline$\bullet \% \$ 41 \mathrm{~K}$ to $<\$ 80 \mathrm{~K}$ & 25.6 & 22.8 & 29.3 \\
\hline$\bullet \%>\$ 80 \mathrm{~K}$ & 45.6 & 43.9 & 49.6 \\
\hline$\%$ female & 57 & 48 & 54 \\
\hline$\%$ white & 81 & 86 & 75 \\
\hline $\begin{array}{l}\% \text { receiving free or } \\
\text { reduced-price lunch }\end{array}$ & 16 & 26 & 17 \\
\hline $\begin{array}{l}\% \text { with Individualized } \\
\text { Education Plans }\end{array}$ & 7 & 6 & 7 \\
\hline$\%$ English home language & 78 & 86 & 77 \\
\hline
\end{tabular}

Note. For age, standard deviations are provided in parentheses. 


\section{TABLE 2}

Means (and standard deviations) by Grade for Observed Variables

\begin{tabular}{|c|c|c|c|}
\hline Observed Variables & Grade 1 & Grade 2 & Grade 3 \\
\hline \multicolumn{4}{|l|}{ Reading comprehension } \\
\hline Gates-MacGinitie & $30.19(6.81)$ & $30.73(5.40)$ & $32.73(9.48)$ \\
\hline WRMT-R/NU passage comprehension & $25.26(7.72)$ & $31.64(6.45)$ & $36.49(6.52)$ \\
\hline Reading Comprehension Measure & $10.24(3.13)$ & $20.58(4.65)$ & $19.13(4.68)$ \\
\hline \multicolumn{4}{|l|}{ Word reading accuracy } \\
\hline WRMT-R/NU word identification & $49.85(12.45)$ & $59.70(9.17)$ & $68.53(9.91)$ \\
\hline WRMT-R/NU word attack & $21.14(8.45)$ & $25.42(8.38)$ & $29.97(7.86)$ \\
\hline \multicolumn{4}{|l|}{ Word reading fluency } \\
\hline TOWRE-2 sight word & $45.63(14.18)$ & $56.85(10.18)$ & $63.50(10.96)$ \\
\hline TOWRE-2 phonemic decoding & $20.23(10.47)$ & $25.07(9.43)$ & $31.20(11.70)$ \\
\hline $\begin{array}{l}\text { Florida Assessment for Instruction in Reading: Oral } \\
\text { Reading Fluency }\end{array}$ & $79.87(34.33)$ & $107.55(37.17)$ & $136.36(37.70)$ \\
\hline \multicolumn{4}{|l|}{ Listening comprehension } \\
\hline Test of Narrative Language-Receptive & $26.73(4.29)$ & $28.90(4.71)$ & $30.76(3.51)$ \\
\hline CELF-4 understanding spoken paragraphs & $6.35(1.12)$ & $6.22(1.77)$ & $6.51(2.03)$ \\
\hline Listening Comprehension Measure & $11.25(2.37)$ & $19.53(4.44)$ & $20.74(5.47)$ \\
\hline \multicolumn{4}{|l|}{ Vocabulary } \\
\hline Peabody Picture Vocabulary Test, fourth edition & $129.23(17.01)$ & $137.56(16.59)$ & $151.12(17.03)$ \\
\hline Expressive Vocabulary Test, second edition & $96.98(14.05)$ & $105.29(13.57)$ & $113.80(14.37)$ \\
\hline CELF-4 word classes & $34.07(4.21)$ & $36.05(3.53)$ & $17.49(5.50)$ \\
\hline
\end{tabular}

Note. CELF-4 = Clinical Evaluation of Language Fundamentals-Fourth Edition; TOWRE-2: Test of Word Reading Efficiency-Second Edition; WRMT-R/NU: Woodcock Reading Mastery Tests-Revised: Normative Update. 
TABLE 3

Word Recognition Model: Standardized Solution ${ }^{a}$ and Global Fit Indexes ${ }^{b}$

\begin{tabular}{|c|c|c|c|c|}
\hline Latent variable & Observed variable & Grade 1 & Grade 2 & Grade 3 \\
\hline \multicolumn{5}{|l|}{ Factor loadings } \\
\hline \multirow{3}{*}{$\begin{array}{l}\text { Reading } \\
\text { comprehension }\end{array}$} & Gates-MacGinitie & .82 & .81 & .92 \\
\hline & WRMT-R/NU passage comprehension & .91 & .82 & .76 \\
\hline & Reading Comprehension Measure & .63 & .70 & .74 \\
\hline \multirow{5}{*}{$\begin{array}{l}\text { Word } \\
\text { recognition }\end{array}$} & WRMT-R/NU word identification & .95 & .88 & .88 \\
\hline & WRMT-R/NU word attack & .72 & .71 & .69 \\
\hline & TOWRE-2 sight word & .93 & .81 & .85 \\
\hline & TOWRE-2 phonemic decoding & .82 & .84 & .86 \\
\hline & $\begin{array}{l}\text { Florida Assessment for Instruction in Reading: Oral } \\
\text { Reading Fluency }\end{array}$ & .93 & .90 & .89 \\
\hline \multirow{3}{*}{$\begin{array}{l}\text { Listening } \\
\text { comprehension }\end{array}$} & Test of Narrative Language-Receptive & .85 & .73 & .60 \\
\hline & CELF-4 understanding spoken paragraphs & .34 & .65 & .68 \\
\hline & Listening Comprehension Measure & .68 & .76 & .83 \\
\hline \multicolumn{5}{|c|}{ Structure coefficients } \\
\hline \multicolumn{2}{|c|}{ Word recognition $\rightarrow$ reading comprehension } & .81 & .48 & .48 \\
\hline \multicolumn{2}{|c|}{ Listening comprehension $\rightarrow$ reading comprehension } & .22 & .57 & .60 \\
\hline \multicolumn{2}{|l|}{$R^{2}$} & .93 & .88 & .86 \\
\hline \multicolumn{5}{|l|}{ Global fit indexes } \\
\hline & CFI & .97 & .97 & .97 \\
\hline & SRMR & .05 & .07 & .06 \\
\hline & $\mathrm{NFI}$ & .96 & .95 & .95 \\
\hline & NNFI & .96 & .95 & .95 \\
\hline
\end{tabular}

Note. CELF-4 = Clinical Evaluation of Language Fundamentals-Fourth Edition; TOWRE-2: Test of Word Reading Efficiency-Second Edition; WRMT-R/NU: Woodcock Reading Mastery Tests-Revised: Normative Update.

${ }^{a}$ All parameter estimates are statistically different from zero $(p<.05)$.

${ }^{\mathrm{b} C o m p a r a t i v e ~ f i t ~ i n d e x ~(C F I), ~ s t a n d a r d i z e d ~ r o o t ~ m e a n ~ s q u a r e ~ r e s i d u a l ~(S R M R), ~ n o r m e d ~ f i t ~ i n d e x ~(N F I), ~ a n d ~}$ nonnormed fit index (NNFI). Acceptable model fit defined as root mean square error of approximation and SRMR < .08 , and $\mathrm{CFI}, \mathrm{NFI}$, and $\mathrm{NNFI}>.90$. 
TABLE 4

Fluency and Accuracy Model: Standardized Solution ${ }^{a}$ and Global Fit Indexes ${ }^{b}$

\begin{tabular}{|c|c|c|c|c|}
\hline Latent variable & Observed variable & Grade 1 & Grade 2 & Grade 3 \\
\hline \multicolumn{5}{|l|}{ Factor loadings } \\
\hline \multirow{3}{*}{$\begin{array}{l}\text { Reading } \\
\text { comprehension }\end{array}$} & Gates-MacGinitie & .82 & .80 & .91 \\
\hline & WRMT-R/NU passage comprehension & .91 & .82 & .77 \\
\hline & Reading Comprehension Measure & .64 & .73 & .73 \\
\hline \multirow{2}{*}{$\begin{array}{l}\text { Word reading } \\
\text { accuracy }\end{array}$} & WRMT-R/NU word identification & .99 & .98 & .99 \\
\hline & WRMT-R/NU word attack & .82 & .81 & .76 \\
\hline \multirow{3}{*}{$\begin{array}{l}\text { Word reading } \\
\text { fluency }\end{array}$} & TOWRE-2 sight word & .93 & .83 & .85 \\
\hline & TOWRE-2 phonemic decoding & .84 & .86 & .85 \\
\hline & $\begin{array}{l}\text { Florida Assessment for Instruction in Reading: Oral } \\
\text { Reading Fluency }\end{array}$ & .93 & .89 & .89 \\
\hline \multirow{3}{*}{$\begin{array}{l}\text { Listening } \\
\text { comprehension }\end{array}$} & Test of Narrative Language-Receptive & .85 & .73 & .61 \\
\hline & CELF-4 understanding spoken paragraphs & .34 & .64 & .68 \\
\hline & Listening Comprehension Measure & .68 & .81 & .83 \\
\hline \multicolumn{5}{|c|}{ Structure coefficients } \\
\hline \multicolumn{2}{|c|}{ Word reading accuracy $\rightarrow$ reading comprehension } & .64 & .47 & $.21^{*}$ \\
\hline \multicolumn{2}{|c|}{ Word reading fluency $\rightarrow$ reading comprehension } & $.17^{*}$ & $.05^{*}$ & .30 \\
\hline \multicolumn{2}{|c|}{ Listening comprehension $\rightarrow$ reading comprehension } & .24 & .57 & .61 \\
\hline \multicolumn{2}{|l|}{$R^{2}$} & .94 & .92 & .88 \\
\hline \multicolumn{5}{|l|}{ Global fit indexes } \\
\hline & CFI & .98 & .97 & .97 \\
\hline & SRMR & .05 & .06 & .06 \\
\hline & $\mathrm{NFI}$ & .96 & .95 & .94 \\
\hline & NNFI & .97 & .95 & .95 \\
\hline
\end{tabular}

Note. CELF-4 = Clinical Evaluation of Language Fundamentals-Fourth Edition; TOWRE-2: Test of Word Reading Efficiency-Second Edition; WRMT-R/NU: Woodcock Reading Mastery Tests-Revised: Normative Update.

${ }^{a}$ All parameter estimates are statistically different from zero $(p<.05)$ except those denoted by *

${ }^{\mathrm{b}}$ Comparative fit index (CFI), standardized root mean square residual (SRMR), normed fit index (NFI), and nonnormed fit index (NNFI). Acceptable model fit defined as root mean square error of approximation and SRMR < .08 , and $\mathrm{CFI}, \mathrm{NFI}$, and NNFI > .90 . 
TABLE 5

Vocabulary Model: Standardized Solution ${ }^{a}$ and Global Fit Indexes ${ }^{b}$

\begin{tabular}{|c|c|c|c|c|}
\hline Latent variable & Observed variable & Grade 1 & Grade 2 & Grade 3 \\
\hline \multicolumn{5}{|l|}{ Factor loadings } \\
\hline \multirow{3}{*}{$\begin{array}{l}\text { Reading } \\
\text { comprehension }\end{array}$} & Gates-MacGinitie & .81 & .81 & .92 \\
\hline & WRMT-R/NU passage comprehension & .84 & .76 & .77 \\
\hline & Reading Comprehension Measure & .62 & .71 & .75 \\
\hline \multirow{5}{*}{$\begin{array}{l}\text { Word } \\
\text { recognition }\end{array}$} & WRMT-R/NU word identification & .95 & .88 & .89 \\
\hline & WRMT-R/NU word attack & .72 & .72 & .69 \\
\hline & TOWRE-2 sight word & .93 & .81 & .84 \\
\hline & TOWRE-2 phonemic decoding & .82 & .84 & .85 \\
\hline & $\begin{array}{l}\text { Florida Assessment for Instruction in Reading: Oral } \\
\text { Reading Fluency }\end{array}$ & .93 & .89 & .88 \\
\hline \multirow{3}{*}{$\begin{array}{l}\text { Listening } \\
\text { comprehension }\end{array}$} & Test of Narrative Language-Receptive & .82 & .73 & .63 \\
\hline & CELF-4 understanding spoken paragraphs & .37 & .63 & .67 \\
\hline & Listening Comprehension Measure & .72 & .76 & .84 \\
\hline \multirow{3}{*}{ Vocabulary } & Peabody Picture Vocabulary Test, fourth edition & .84 & .89 & .86 \\
\hline & Expressive Vocabulary Test, second edition & .94 & .82 & .82 \\
\hline & CELF-4 word classes & .48 & .52 & .82 \\
\hline \multicolumn{5}{|c|}{ Structure coefficients } \\
\hline \multicolumn{2}{|c|}{ Word recognition $\rightarrow$ reading comprehension } & .81 & .50 & .46 \\
\hline \multicolumn{2}{|c|}{ Listening comprehension $\rightarrow$ reading comprehension } & .26 & .61 & .61 \\
\hline \multicolumn{2}{|c|}{ Vocabulary $\rightarrow$ word recognition } & .68 & .51 & .67 \\
\hline \multicolumn{2}{|c|}{ Vocabulary $\rightarrow$ listening comprehension } & .83 & .93 & .78 \\
\hline \multicolumn{2}{|c|}{$R^{2}$ for reading comprehension } & .96 & .91 & .88 \\
\hline \multicolumn{2}{|c|}{$R^{2}$ for word recognition } & .47 & .27 & .45 \\
\hline \multicolumn{2}{|c|}{$R^{2}$ for listening comprehension } & .70 & .87 & .61 \\
\hline \multicolumn{5}{|l|}{ Global fit indexes } \\
\hline & CFI & .97 & .96 & .97 \\
\hline & SRMR & .06 & .08 & .05 \\
\hline & NFI & .95 & .93 & .95 \\
\hline & NNFI & .96 & .94 & .97 \\
\hline
\end{tabular}

Note. CELF-4 = Clinical Evaluation of Language Fundamentals-Fourth Edition; TOWRE-2: Test of Word Reading Efficiency-Second Edition; WRMT-R/NU: Woodcock Reading Mastery Tests-Revised: Normative Update.

${ }^{a}$ All parameter estimates are statistically different from zero $(p<.05)$. 
${ }^{b}$ Comparative fit index (CFI), standardized root mean square residual (SRMR), normed fit index (NFI), and nonnormed fit index (NFI). Acceptable model fit defined as root mean square error of approximation and $\mathrm{SRMR}<.08$, and $\mathrm{CFI}, \mathrm{NFI}$, and $\mathrm{NNFI}>.90$. 


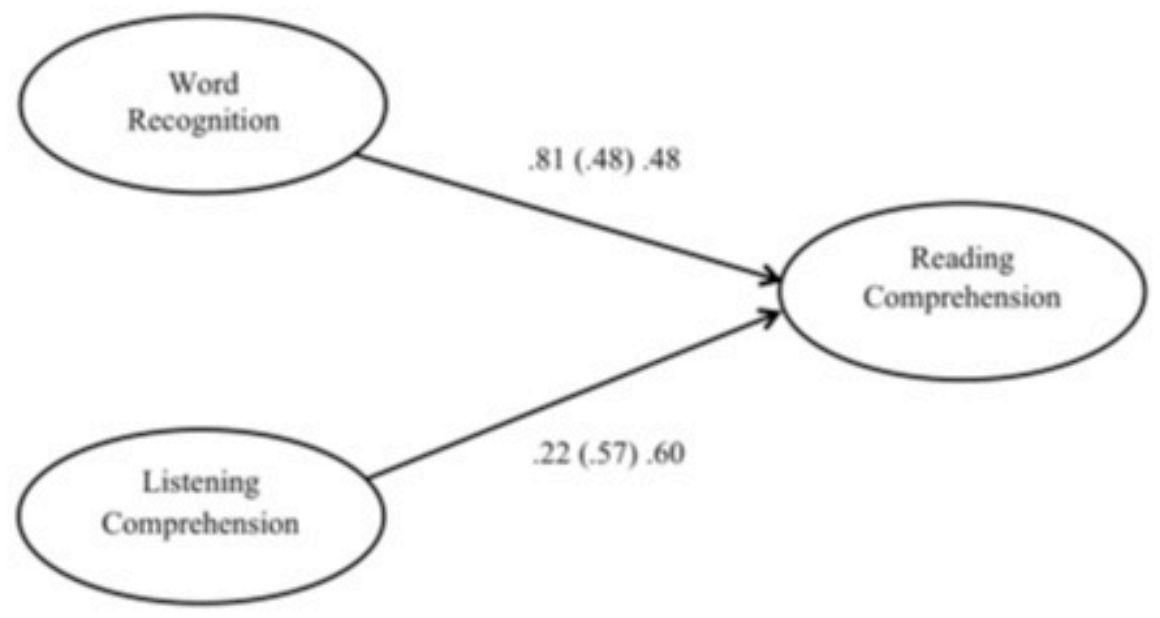




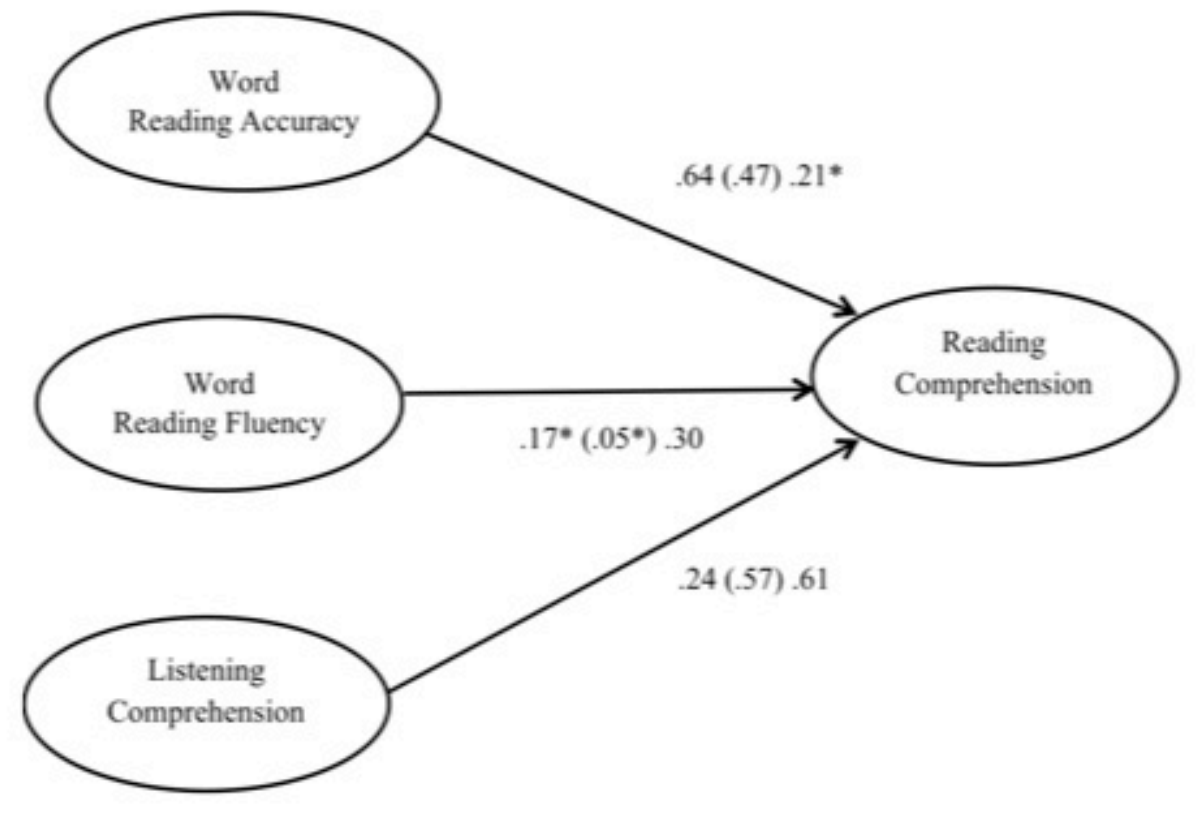




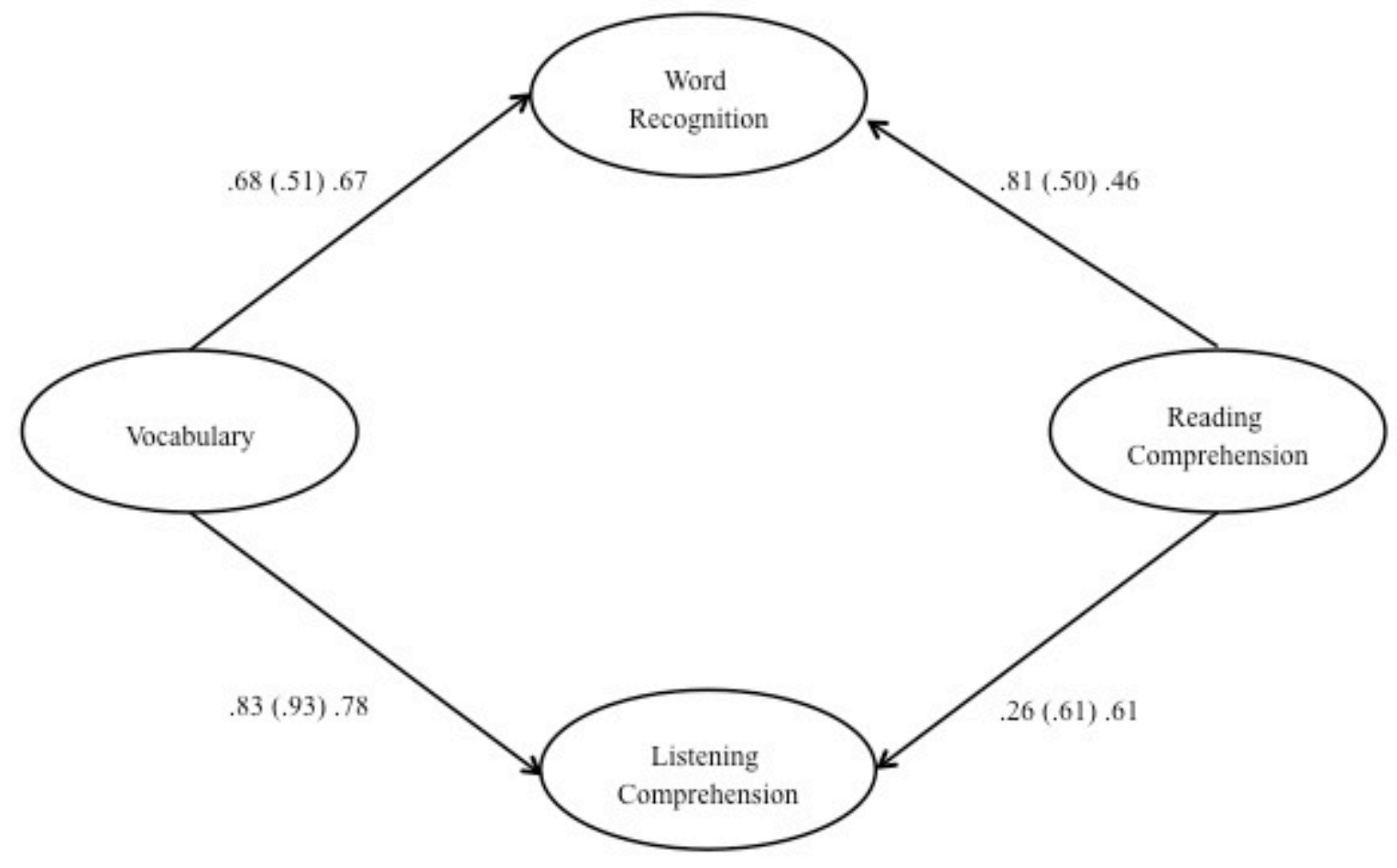




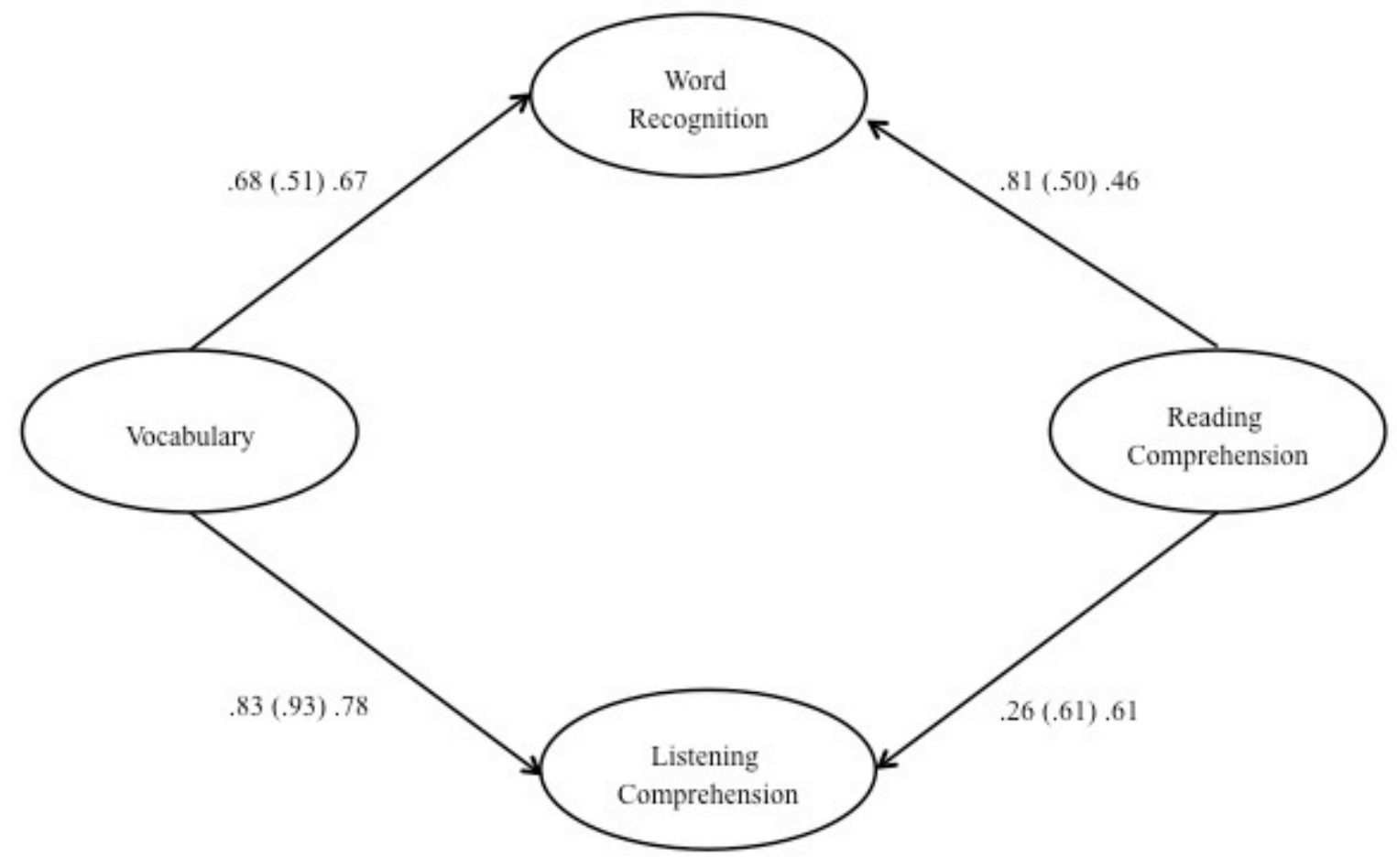

